\title{
The expectation of future precipitation change over the Mediterranean region is different from what we observe
}

\author{
Armineh Barkhordarian • Hans von Storch • \\ Jonas Bhend
}

Received: 10 October 2011/Accepted: 11 August 2012/Published online: 4 September 2012

(C) The Author(s) 2012. This article is published with open access at Springerlink.com

\begin{abstract}
In this study we assess the role of anthropogenic forcing (greenhouse gases and sulphate aerosols, GS) in recently observed precipitation trends over the Mediterranean region. We investigate whether the observed precipitation trends (1966-2005 and 1979-2008) are consistent with what 22 models project as response of precipitation to GS forcing. Significance is estimated using 9,000-year control runs derived from the CMIP3 archive. The results indicate that externally forced changes are detectable in observed precipitation trends in winter, late summer and in autumn. Natural internal climate variability cannot explain these changes. However, the observed trends (derived from 3 sources) are markedly inconsistent with expected changes due to GS forcing. While the influence of GS signal is detectable in winter and early spring, observed changes are several times larger than the projected response to GS forcing. The most striking inconsistency, however, is the contradiction between projected drying and the observed increase in precipitation in late summer and autumn, irrespective of the data set used. Natural (internal) variability as estimated from the models cannot account for these inconsistencies, which are already present in the large scale circulation patterns (Geopotential
\end{abstract}

\footnotetext{
A. Barkhordarian $(\bowtie) \cdot H$. von Storch Institute for Coastal Research,

Helmholtz Zentrum Geesthacht,

Geesthacht, Germany

e-mail: armineh.barkhordarian@hzg.de

H. von Storch

KlimaCampus, Hamburg, Germany

J. Bhend

Centre for Australian Weather and Climate Research, CSIRO Marine and Atmospheric Research,

Aspendale, VIC, Australia
}

height at $500 \mathrm{hPa}$ ). The obtained results are robust to the removal of the fingerprint of the North Atlantic Oscillation. The detection of an outright sign mismatch of observed and projected trends in autumn and late summer, leads us to conclude that the recently observed trends can not be used as an illustration of plausible future expected change in the Mediterranean region. These significant shortcomings in our understanding of recent observed changes complicate communication of future expected changes in Mediterranean precipitation.

Keywords Mediterranean · Precipitation · Detection

\section{Introduction}

The issue of future climate change in general is an issue of broad interest-satisfying a general intellectual curiosity but also having much to do with practical managerial decisions about how to plan, design and shape our future on global to local scales. In this study, we examine to what extent the present climate change "is on the way" towards conditions described by the climate change scenarios at the end of this century. We have earlier determined that observed recent (1980-2009) warming over the Mediterranean region has very likely an anthropogenic origin and thus will likely continue to rise, albeit not in a monotonous manner (Barkhordarian et al. 2012).

The high natural variability of Mediterranean climate in both space and time, which leads to low signal-to-noise ratio of externally forced changes compared to internal variability, makes both the detection of climate change and attribution of its causes very difficult, significantly for nontemperature parameters such as precipitation, for which the response to the forcing is weak relative to the background 
variability (Hegerl and Zwiers 2011). Nonetheless, observations suggest that climate may already be changing in the region, with long-term trends in near-surface temperature (Barkhordarian et al. 2012), mean sea level pressure (Barkhordarian 2012) and surface specific humidity (Barkhordarian et al. submitted) that cannot be explained by long-term natural variability (in some seasons).

At the global scale, there is evidence for a detectable influence of both short-wave (primarily natural) forcing on observed precipitation trends and also long-wave greenhouse gas (GHG) forcing. It has been shown by Zhang et al. (2007) that anthropogenic forcing contributed significantly to observed increases in zonal mean land precipitation in the Northern Hemisphere mid-latitudes and drying in the Northern Hemisphere subtropics and tropics. Internal climate variability or natural forcing cannot explain these changes. The CMIP3 simulations, however, underestimate the observed change. A more recent study by Min et al. (2011) found that human-induced increases in GHGs have contributed to the observed intensification of heavy precipitation events over two-thirds of the datacovered parts of northern hemisphere land areas. As with mean precipitation, they also found that models underestimate the observed precipitation change.

On the other hand, the studies by Lambert et al. (2004, 2005), indicate that short-wave forcing of the climate system such as changes in volcanic aerosols or solar irradiance has a larger effect on global precipitation than GHG long-wave forcing. Lambert et al. (2004) detect a response to combined anthropogenic and natural forcing in the observed record from 1944-1997 (and more weakly so from 1908-1997). They suggest that natural forcing, in particular the response to stratospheric aerosols due to volcanic activity, is the dominant forcing in the 20th century precipitation record. This supports the findings of Gillett et al. (2004), who were able to formally attribute the observed global land precipitation changes over the 20th century to volcanic forcing, but not to anthropogenic GHGs and sulphates or solar forcings.

At smaller spatial scales, however, there is critical uncertainty in the attribution of regional observed precipitation changes (Hegerl and Zwiers 2011). Analysis of the CMIP3 ensemble of models shows that the Mediterranean region is one of the most prominent climate change hotspots, i.e. one of the most responsive regions to global warming (Giorgi 2006). Study by Gao and Giorgi (2008) indicates that under the greenhouse gas forcing by the end of the $21 \mathrm{st}$ century the Mediterranean region might experience a substantial increase and northward extension of arid regimes. This is mostly because of a large decrease of precipitation during the spring and summer seasons (Giorgi and $\mathrm{Bi}$ 2005).

The method used in this study has been earlier applied to near-surface temperature (Barkhordarian et al. 2012) and mean sea level pressure (Barkhordarian 2012). Here we analyze precipitation trends and investigate whether the observed changes are likely to have been due to natural (internal) variability alone, and if not, whether they are consistent with what models simulate as response of precipitation to anthropogenic (GS) forcing. Therefore, we compare trends in observed precipitation with the response to GS forcing derived from the set of global climate model simulations provided through the World Climate Research Programme's (WCRP) Coupled Model Intercomparison Project 3 (CMIP3 Meehl et al. 2007). Consistency of observed trends with climate change projections would point to the plausibility that the recent trend will continue into the future-based on the understanding that the recent trend is related to anthropogenic forcing (GS), which will continue in the future (Bhend and von Storch 2008). For the first time this method is being applied to Mediterranean precipitation. While recent studies have often focused on winter and summer only, here we analyze trends in sliding 3-month windows.

\section{Observations and model data}

The Mediterranean area is defined here as the region from $25^{\circ} \mathrm{N}$ to $50^{\circ} \mathrm{N}$ and $10^{\circ} \mathrm{W}$ to $40^{\circ} \mathrm{E}$ (See Fig. 3). Observations are subject to uncertainty; in this study this uncertainty is addressed by using three independently developed observed data sets. We use land-only rain gauge data from the latest version of the Climatic Research Unit's (CRU) gridded high-resolution $\left(0.5^{\circ}\right.$ by $\left.0.5^{\circ}\right)$ dataset CRU TS 3.10 (Mitchell and Jones 2005, referred to as CRU3.1 in the following). The station records of the CRU3.1 dataset are quality controlled and homogenized, using an automated method developed from the GHCN method (Easterling and Peterson 1995).

We also use version 5 of the "Full Data Reanalysis Product" of the Global Precipitation Climatology Centre (GPCC Rudolf et al. 2005). These data include quality controlled rain gauge data from 1901-2009 that have been interpolated to a $0.5^{\circ}$ by $0.5^{\circ}$ grid using the SPHEREMAP method (Willmott et al. 1985).

Furthermore, we use monthly mean precipitation over land and sea areas from the Global Precipitation Climatology Project (GPCP Adler et al. 2003). The GPCP dataset provides rain gauge-satellite merged data in $2.5^{\circ}$ by $2.5^{\circ}$ grids over the period 1979-2008. Rain-gauge data are quality controlled to contribute to the analysis over land.

CRU has advised the users of CRU TS2.1 that it is not suitable for detection and attribution, as the effect of urban development and land use changes are potentially present in the data, however, there is no published study exploring this issue further. The main difference between CRU TS2.1 
and CRU TS3.1 version is that no new homogenization is explicitly performed on the latter. Existing homogenizations in the underlying datasets, and those additionally performed by national meteorological agencies prior to releasing their station data, are incorporated. Thus, the station series of CRU TS3.1 might still be affected by urban development and land use changes. In addition the rain-gauge data of GPCC5 and GPCP data sets are quality controlled, which does remove outliers, but does not ensure homogeneity. Thus, our results must be interpreted with the caveat of potential inhomogeneity of the currently available gridded precipitation data sets. However, we expect that most of the in-homogeneities are not systematic.

For all datasets, trends have been calculated using ordinary least squares linear regression and the units are $\mathrm{mm} /$ decade. To describe expected anthropogenic trends, we use global projections based on the IPCC SRES A1B (A2) scenario, ending with a $\mathrm{CO} 2$ concentration of 720 (850) ppm by the year 2100, obtained from 22 (18) global Atmosphere-Ocean General Circulation Models (AOGCMs). The simulations are included in the CMIP3 multi-model dataset (Meehl et al. 2007). Previous to the analysis, the model data are interpolated to a latitude-longitude grid with a resolution of $0.5^{\circ}$ (or in case of GPCP, $2.5^{\circ}$ ) using conservative remapping (Jones 1999). We mask grid cells in the monthly data according to the missing value mask in the observed record.

\section{Methodology}

We follow the same approach as presented in Barkhordarian et al. (2012). In the first step, we investigate whether the observed changes are derived from an undisturbed stationary climate. This is handled by testing the null hypothesis $H_{0}$ : zero trend. To test the null hypothesis, annual and seasonal observed precipitation trends are compared with estimated natural (internal) variability, derived from control integrations of CMIP3 climate models. Control integrations are experiments with all external forcings fixed to the values attained in 1850 reflecting preindustrial conditions.

Estimating natural (internal) variability from long control simulations has been a popular method, since the experiment setup is sound and long simulations (and thus precise estimates) are possible (Stone et al. 2009). However, the verification of variability of global climate models is difficult since the instrumental record for precipitation is not long enough (100-year) to give a reliable estimate of internal variability, while paleoclimatic data are sparse and often of limited quality [see e.g. Hegerl et al. (1996)].

From 9,000 simulated years of control runs that are sufficiently long to resolve variability on all relevant timescales, we draw 285 non-overlapping 30-year segments (or 213 non-overlapping 40-year segments) to estimate internal variability, i.e. stochastic variability that would be present irrespective of any external influence on the climate system (Hegerl and Zwiers 2011). In order to remove the potential drift in coupled atmosphere-ocean models, a de-trending treatment is applied to the control simulations. Independent control run segments are calculated in such a way as to mimic the observations using the same observation mask to account for the effects of missing data. A list of the climate models and the number of years used from control integrations to estimate the internal variability is given in Table 1 .

Rejecting the null hypothesis $H_{0}$ : zero trend, indicates that the observed changes can not be explained by internal variability alone and externally forced changes are detectable. Once it is found that external forcings must be invoked (are detectable) for explaining recent trends, in the second step we assess whether the observed significant trends are within the range of expected changes due to anthropogenic forcing (Greenhouse gases and Sulphate aerosols, GS) generated by 22 climate models (Sect. 2). To this end, we compare area-mean changes of observed precipitation in 3-month windows over the period 1966-2005 (over land) and 1978-2009 (over land and sea) with what climate models project as response of precipitation to anthropogenic (GS) forcing. We consider a large number of A1B (22) and A2 (18) simulations. If the recent observed trends reside in this range of possible and plausible changes due to increasing greenhouse gas and sulfate aerosol concentrations, we call the observed change consistent with GS forcing.

In order to take the spatial pattern of change into account, we use regression indices as a pattern similarity statistic ( $R$, Eq. 1).

$R(O, P)=\frac{\sum_{i=1}^{n} P_{i} \cdot O_{i}}{\sum_{i=1}^{n} P_{i}^{2}}$

The index subscript $i=1, \ldots, n$ counts the spatial points, $O_{i}$ and $P_{i}$ refer to the observed and simulated pattern of change, respectively.

The distribution of the regression indices is assessed from fits of the regression model (Eq. 1) to non-overlapping control run segments derived from long control simulations. We use the combination of the quantiles of control run trends and the fit to the observations to test the null hypothesis that the uncertainty range of regression indices does not include " 0 ", indicating that the influence of GS signal is detectable in the observed record (see Fig. 4). To examine if anthropogenic (GS) forcing is a plausible explanation for the observed change, we evaluate the hypothesis $H_{d}$ that the regression of the observed trend on the GS signal does not include " 0 " but includes " 1 " 
Table 1 The 22 coupled oceanatmopsphere models used in this study along with the number of twentieth century runs per model, and the number of years and independent segments of the control runs used in this study to estimate natural (internal) variability

\begin{tabular}{lll}
\hline & Models (number of runs) & Number of years used from control integrations \\
\hline 1 & bccr-bcm2.0 (1) & 250 (8 segments of 30-year or 6 segments of 40-year) \\
2 & cccma-cgcm3.1 (5) & 1,000 (33 segments of 30-year or 26 segments of 40-year) \\
3 & cccma-cgcm3.1-T63 (1) & 350 (11 segments of 30-year or 8 segments of 40-year) \\
4 & cnrm-cm3 (1) & 500 (16 segments of 30-year or 12 segments of 40-year) \\
5 & csiro-mk3.0 (1) & 350 (11 segments of 30-year or 9 segments of 40-year) \\
6 & csiro-mk3.5 (1) & 1,000 (33 segments of 30-year or 26 segments of 40-year) \\
7 & gfdl-cm2.0 (1) & 500 (16 segments of 30-year or 12 segments of 40-year) \\
8 & gfdl-cm2.1 (1) & 500 (16 segments of 30-year or 12 segments of 40-year) \\
9 & giss-aom (2) & 250 (8 segments of 30-year or 6 segments of 40-year) \\
10 & giss-model-e-h (3) & 380 (12 segments of 30-year or 9 segments of 40-year) \\
11 & ingv-echam4 (1) & 100 (3 segments of 30-year or 2 segments of 40-year) \\
12 & inmcm3.0 (1) & 350 (11 segments of 30-year or 8 segments of 40-year) \\
13 & ipsl-cm4 (1) & 500 (16 segments of 30-year or 12 segments of 40-year) \\
18 & miroc3.2-hires (1) & 100 (3 segments of 30-year or 2 segments of 40-year) \\
15 & miroc3.2-medres (3) & 500 (16 segments of 30-year or 12 segments of 40-year) \\
16 & miub-echo-g (3) & 350 (11 segments of 30-year or 8 segments of 40-year) \\
17 & mpi-echam5 (4) & 500 (16 segments of 30-year or 12 segments of 40-year) \\
18 & mri-cgcm2.3-2a (5) & 350 (11 segments of 30-year or 8 segments of 40-year) \\
19 & ncar-ccsm3.0 (7) & 230 (7 segments of 30-year or 5 segments of 40-year) \\
20 & ncar-pcm1 (4) & 350 (11 segments of 30-year or 8 segments of 40-year) \\
21 & ukmo-hadcm3 (1) & 350 (11 segments of 30-year or 8 segments of 40-year) \\
22 & ukmo-hadgem1 (1) & 160 (5 segments of 30-year or 4 segments of 40-year) \\
& & Total: 285 non-overlapping 30-year segments \\
& & Total: 213 non-overlapping 40-year segments \\
\hline
\end{tabular}

(Hegerl et al. 1997). When there is insufficient evidence to reject $H_{d}$, we claim that the observed change is consistent with climate change projections. If recent trends and scenarios are inconsistent, however, we conclude that the observed recent change cannot be interpreted as a harbinger of future change.

\subsection{Anthropogenic climate change signal estimates}

In this study, two methods are used to estimate the anthropogenic (GS) signal. On the one hand, we use timeslice experiments and define the anthropogenic climate change signal as the difference between the last decades of the 21st century (2071-2100) and the reference climatology (1961-1990). We assume a linear development from 1961-2100 and the resulting signal is scaled to change per year (Bhend and von Storch 2008). The linearity assumption is supported by the study of Raisanen et al. (2004) and Cubasch et al. (2001). Using well-separated time slices, 110 years in this study, has the advantage of increasing the signal-to-noise ratio and avoiding the need to average multiple models to get clear signal patterns. A list of the climate models and the number of ensemble members of the individual models, is given in Table 1. For each model, these ensemble members differ only in the initial conditions and thus represent different realizations of internal variability. Therefore, by averaging over an ensemble of runs the signal to noise ratio of externally forced changes compared to internal variability is further increased. The multi-model CMIP3 archive offers unique opportunities. A key opportunity is that the archive contains information from models with different resolution, physics, parameterizations and forcings. This method allows us to best exploit this wealth of information by explicitly dealing with individual models separately.

On the other hand, we estimate the anthropogenic signal from transient model simulations, forced with historical anthropogenic forcing only (ANT, greenhouse gases and sulphate aerosols), over the time period 1979-2008 and 1966-2005. The multi-model ensemble mean is used here to get model simulated response patterns with high signalto-noise ratio of externally forced changes compared to internal variability (Gillett et al. 2002). Here we use the multi-model ensemble mean of 10 models (18 ANT simulations) derived from the CMIP3 archive. The models used are, BCCR-BCM2.0 (1 run), CNRM-CM3 (1 run), CSIRO-MK3.0 (1 run), CSIRO-MK3.5 (1 run), GISSAOM (2 runs), INGV-ECHAM4 (1 run), ECHAM5/ MPI-OM (4 runs), CCCMA-CGCM3.1 (5 runs), CCCMA- 
CGCM3.1-T63 (1 run) and UKMO-HadGEM1 (1 run). The strategy used to compute multi-model mean is based on giving each model equal weight. Thus, the multi-model mean response is not dominated by responses of models with many simulations. The formula to compute effective number of models with equal weighting of the individual models is: $n=\frac{m^{2}}{\sum_{i=1}^{m} \frac{1}{l_{i}}}$, where $\mathrm{m}$ is the number of models and 1 is the ensemble size (Allen and Tett 1999). The final internal variance is then just $1 / \mathrm{n}$ the internal variance. Thus, by using the multi-model mean of 10 models (18 ANT simulations), the internal variability decreases by more than $90 \%$ compared to using an individual simulation, which increases the signal-to-noise ratio in estimated anthropogenic patterns considerably.

Since the 20th century simulations generally finished in 1999 (2000), it was necessary to use outputs from SRES A1B scenario for the last 8 (5) years of the simulation period. Thus, we combine the 20th century historical runs with the projections for the 21st century driven by anthropogenic (GS) forcings according to the SRES A1B emission scenario. The A1B runs provide a reasonable estimate of GHG forcings over 2000-2010 (Santer et al. 2011), but it is not clear how realistically they represent the true net aerosol forcing over this period (Santer et al. 2011), thus splicing together output from the 20th century and A1B simulations can introduce forcing discontinuities (Arblaster et al. 2011).

\section{Results}

\subsection{Detection of externally forced changes}

Figure 1 shows observed area-mean changes of precipitation over land in 3-month windows for the period from 1966 to 2005 based on the CRU3.1 and GPCC5 datasets. The grey bars represent the mean value of CRU3.1 and GPCC5, with trends from each dataset corresponding to the brown bars. The datasets generally agree well, with notable differences in JJA, JAS, ASO and NDJ. Both datasets suggest that the area mean precipitation decreases in all sliding 3-month windows from December to August (DJF, JFM, ..., JJA). The general drought conditions in the wet season since the 1960s over large part of the Mediterranean region is a consistent finding among other studies (e.g. Xoplaki et al. 2004; Mariotti 2010; Hoerling et al. 2012). In late summer and autumn, however, the observations suggest an increase in the amount of precipitation in JAS, ASO, SON and OND over the 1966-2005 period.

Here we assess whether externally forced changes have a detectable influence on the observed trends by comparing observed trends with those calculated from pre-industrial control simulations (see Sect. 3). We analyze 9,000 years of control integrations and derive 213 non-overlapping 40-year trends in an undisturbed stationary climate (Table 1). The observed trend is likely not due to natural

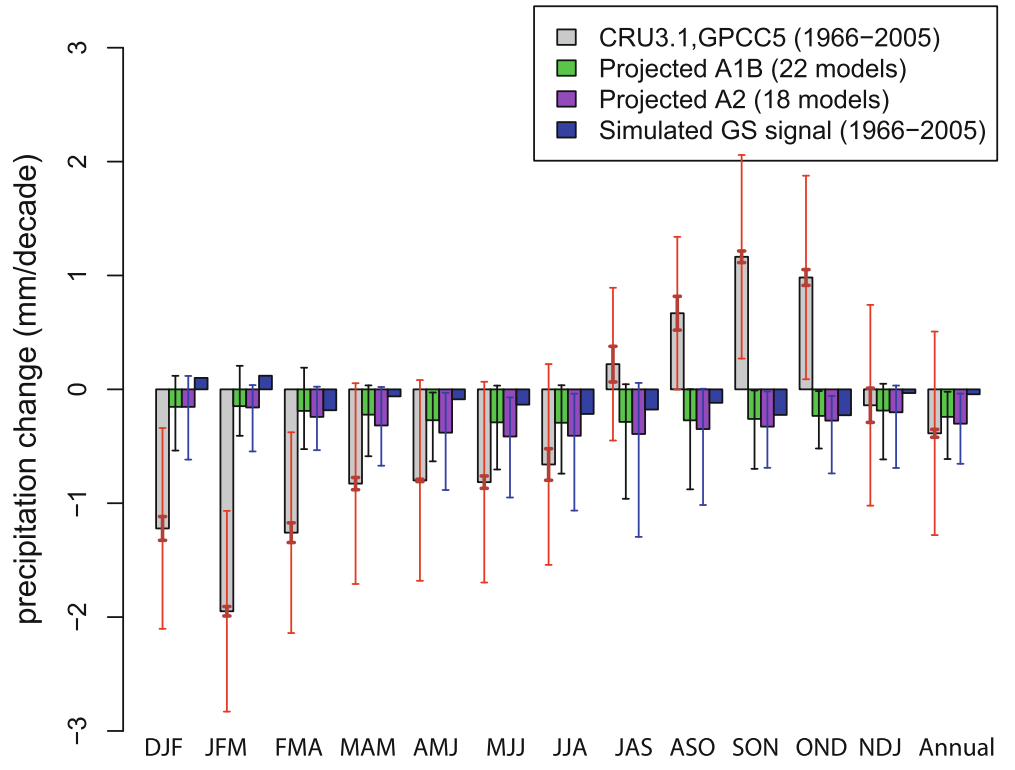

Fig. 1 Observed trends in precipitation over land in the Mediterranean from 1966 to 2005 (in mm/decade) for sliding 3-month windows (grey bars) in comparison with the anthropogenic (GS) signal estimated from CMIP3 simulations. The GS signal has been derived from time slices of simulations according to the A1B (green bars) and A2 (purple bars) scenarios and from the multi-model mean of transient simulations from 10 CMIP3 models with anthropogenic forcing only (blue bars). The brown whiskers denote the spread of trends of the two observational datasets (CRUv3, GPCC5). The black and blue whiskers show the spread of trends of $22 \mathrm{~A} 1 \mathrm{~B}$ and $18 \mathrm{~A} 2$ climate change projections. The red whiskers indicate the $90 \%$ confidence interval of observed trends, derived from model-based estimates of natural (internal) variability (213 non-overlapping 40 -year segments derived from 9,000 years of control integration) 
Fig. 2 According to Fig. 1 but for observed trend in precipitation over land and sea from 1979 to 2008 according to the GPCP dataset. The red whiskers indicate the $90 \%$ confidence interval of observed trends, derived from modelbased estimates of natural (internal) variability (285 nonoverlapping 30-year segments derived from 9,000 years of control integration)

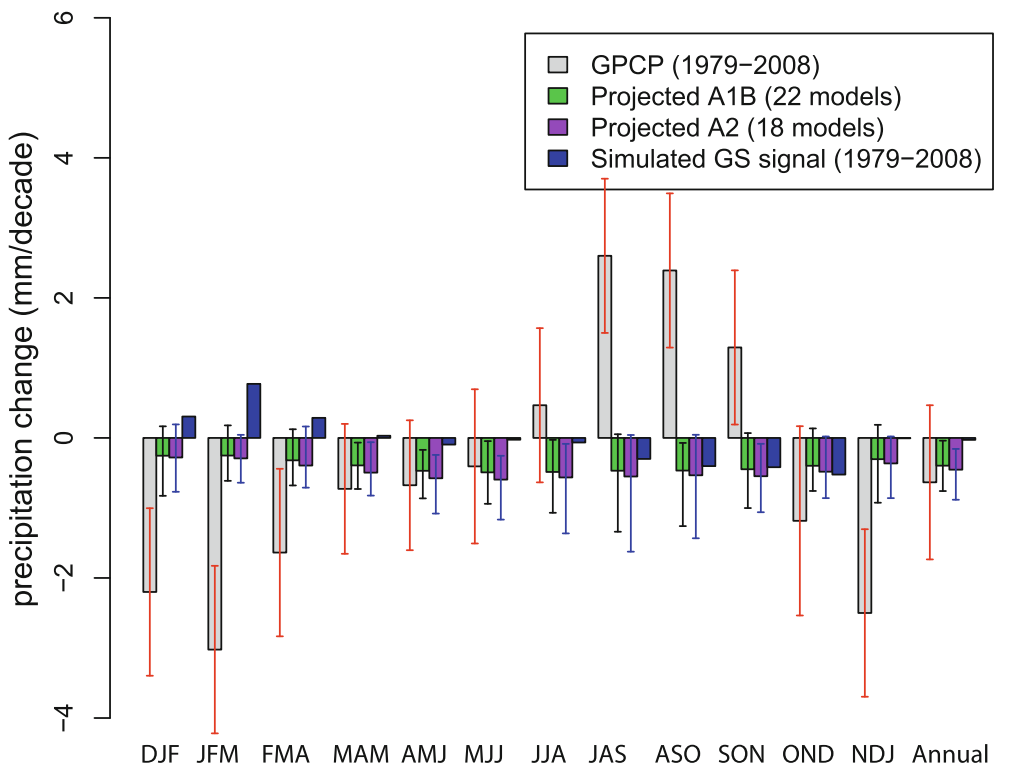

(internal) variability alone in cases for which the $90 \%$ uncertainty range about the observed trends (red whiskers in Figs. 1, 2) excludes zero. In DJF, JFM and FMA, the observed trends are highly unlikely due to internal variability alone, noting that no single sample of 213 segments yield a negative trend of precipitation as strong as that observed.

Also in autumn (SON and OND) the uncertainty range of observed trends derived from control runs does not include zero with both CRU3.1 and GPCC5. This indicates that the observed positive trends in the amount of precipitation in SON and OND intervals deviate significantly (at $5 \%$ level, one-sided test) from natural (internal) variability. In ASO the mean value of both datasets are significantly different from internal variability, and also GPCC5 displays a significantly greater than zero positive trend, however the observed trend derived from CRU3.1 is not significant (Fig. 1). Therefore, we conclude that it is unlikely that the observed negative trends in winter and positive trends in autumn can be attributed to natural (internal) variability alone and externally forced changes are significantly detectable.

We have also analysed the GPCP dataset incorporating precipitation over sea (Fig. 2). Over the period 1979-2008, GPCP displays a negative trend in all sliding 3-month windows (over land and sea) from November to June (NDJ, DJF, ..., MJJ). Consistent with CRU3.1 and GPCC5 datasets, GPCP also displays a positive trend in late summer and autumn (JJA, JAS, ASO and SON). As displayed by the red whiskers in Fig. 2, the statistical test indicates that the observed trends in winter (NDJ, DJF, JFM), early spring (FMA), late summer (JAS) and autumn (ASO, SON) are detected at the $5 \%$ level (one-sided test). That is, there is less than a $5 \%$ probability of such a large trend due to natural (internal) variability alone according to $285 \mathrm{seg}$ ments of unforced trends (derived from 9,000 years of control simulations).

Thus, the merged rain gauge and satellite record according to GPCP along with the station based records, CRU3.1 and GPCC5, are suggesting that the observed changes in winter, late summer and autumn exceed the limits of natural (internal) variability. That is, externally forced changes are detectable (at $5 \%$ significant level, one-sided test). In the following, we assess whether the observed trends, which are found to be inconsistent with natural (internal) variability, are consistent with climate change scenarios.

\subsection{Consistency of observed and projected area-mean changes}

Here we analyze whether the CMIP3 projections encompass the observed trends the magnitude of which can not be reconciled with natural (internal) variability alone. To this end, we compare the observed trends with what climate change scenarios project as response of precipitation to GS forcing (Figs. 1, 2). With a few exceptions, all A1B (A2) scenarios from the 22 (18) models used project negative trends in all 3-month windows. Under increasing GHG concentrations we thus expect drier conditions in the region, with maximum decreases in precipitation in the warm season and minimum decreases in the cold season. This indicates clearly that warm season precipitation is expected to be more responsive to GS forcing.

Figure 3 shows maps of change for the GPCP and CRU3.1 datasets as well as the spatial pattern of the 
anthropogenic climate change signal (GS) derived from the multi-model ensemble mean of 22 models (49 ensemble members). In most simulations, as in the multi-model ensemble mean shown in Fig. 3, wintertime precipitation is projected to increase in a narrow band in the northern part of the Mediterranean and is projected to decrease in the remaining area with large reductions in areas at the western border of the region (southern Spain, northern Algeria and Morocco) and over Turkey. Giorgi and Lionello (2008) and Mariotti (2010) confirm this meridional contrast in precipitation change with drying in the south and wettening in the north. Lionello and Giorgi (2008) suggests that the increase of the winter (DJF) cyclone activity in future climate scenarios over western Europe is responsible for the larger precipitation at the northern coast of the Mediterranean, while the reduction of cyclone activity inside the Mediterranean region in future scenarios is responsible for the lower precipitation at the southern coast. Also, such a south-north contrast in European wintertime (DJF and FJM) precipitation trends is seen with observed records (Fig. 3). The spatial pattern of precipitation suggested by CRU3.1 and GPCC5 is characterized by a meridional dipole of increase in the northern Europe and strong decrease of precipitation over Southern Europe and northern Algeria and Morocco.

When comparing the observed and projected area-mean changes as shown in Fig. 1, the trends derived from the observed record display a negative trend in the annual amount of precipitation which can be attributed to internal variability alone. This is in agreement with the study by Zhang et al. (2007), which indicates that there has been no detected change in the zonal averages of annual land precipitation during 1925-1999 within the extratropical band $30^{\circ} \mathrm{N}-50^{\circ} \mathrm{N}$. The disagreement between observed and projected changes are considerably worse when 3-monthly means are considered. The CRU3.1 and GPCC5 datasets show a large negative trend in total winter precipitation in DJF, JFM and FMA months. These trends are greater than the central $90 \%$ of unforced trends derived from modelbased estimates of natural (internal) variability. In addition, the multi-model ensemble mean projections strongly underestimate the observed trends by a factor of $\sim 6, \sim 9$ and $\sim 5$ in DJF, JFM and FMA respectively (Fig. 1).

The wintertime precipitation trends derived from the GPCP dataset are also strongly and consistently underestimated by the projections (Fig. 2). GPCP displays negative trends in the NDJ, DJF, JFM and FMA intervals which are significantly (at $5 \%$ level, one-sided test) different than natural (internal) variability and several times larger than the ensemble mean of the projections.

A warm season drying signal over the Mediterranean is a remarkably consistent feature in the last few generations of global (Giorgi et al. 2001; Giorgi and Bi 2005) and regional climate change projections (Deque et al. 2005; Somot et al. 2008; Gao and Giorgi 2008). As reported in the IPCC AR4 (Christensen et al. 2007), the risk of summer drought is likely to increase in the Mediterranean area. In spite of this, we find a notable discrepancy in late summer (JAS) when observations display a positive trend $(+2.8 \mathrm{~mm} / \mathrm{month}$ per decade) in the amount of precipitation over the period 1979-2008 according to the GPCP dataset. Natural (internal) variability cannot explain the observed change. As displayed in Fig.3, precipitation increases throughout the region in JAS from 1979 to 2008 with a more pronounced increase in the northern part.

This contradiction extends into autumn. In SON we find an important difference, namely those trends of observed precipitation amounts contradict the projections in terms of both sign and intensity of the trends. There is a significant (at $5 \%$ level) increase in the precipitation amount in the CRU3.1, GPCC5 and GPCP data sets (together with an increase in the total number of wet days; not shown). The increase of precipitation is significant in the northeast and southwest parts of the region, while decreases of precipitation are seen over parts of the central Mediterranean, which is pronounced over Italy, north of Algeria and Tunisia (Fig. 3). In contrast to these upward trends, all climate change projections according to both the A1B and A2 scenarios describe increasingly drier and stable conditions in autumn.

As outlined in Sect. 1, we further evaluate the robustness of the results against estimating the anthropogenic signal from transient simulations of 20th century climate solely forced with anthropogenic forcing. As shown in Figs. 1, 2, climate models suggest an increase in precipitation in response to GS forcing in winter (DJF and JFM). The response to GS forcing derived from the transient simulations is strongly at odds with the observed negative trends in the cold season. In contrast, trends in the GS response derived from time slices are predominantly negative albeit much weaker than the observed decrease in winter. In some 3-month intervals, the simulated response to GS forcing is almost zero, although this result from the disagreement of the climate models and the cancelation of trends that have opposite signs. The contradiction is also striking in late summer and autumn, when both approaches to derive the GS response result in negative trends in the amount of precipitation, in contrast with the observed increase. Therefore, we conclude that the inconsistency of observed trend patterns with GS signal patterns in winter and late summer and autumn are robust against the approach used to estimate the GS response. However, results must be interpreted with the caveat of forcing discontinuities due to splicing together output from the 20th century and A1B simulations (Arblaster et al. 2011). 
Fig. 3 From left to right Seasonal observed pattern of precipitation change over the period 1979-2008 based on observed precipitation change over the period 1966-2005 based on CRU3.1, ensemble mean anthropogenic (GS) signal pattern derived from 22 models, and the anthropogenic (GS) signal pattern derived from the INGV coupled regional model, according to SRES A1B scenario
GPCP (1979-2008)

CRU3.1 (1966-2005)
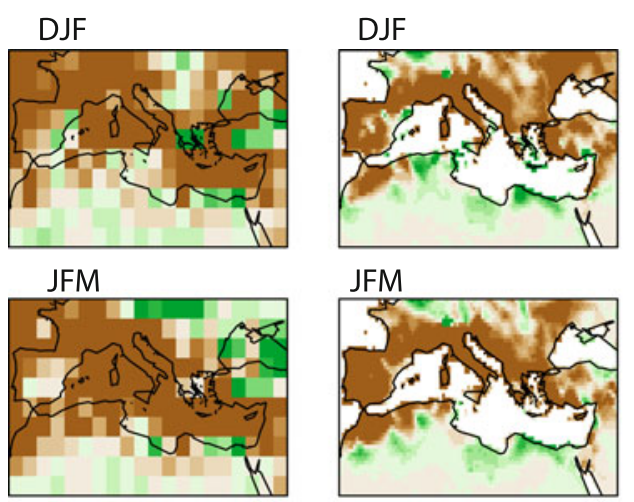

JAS
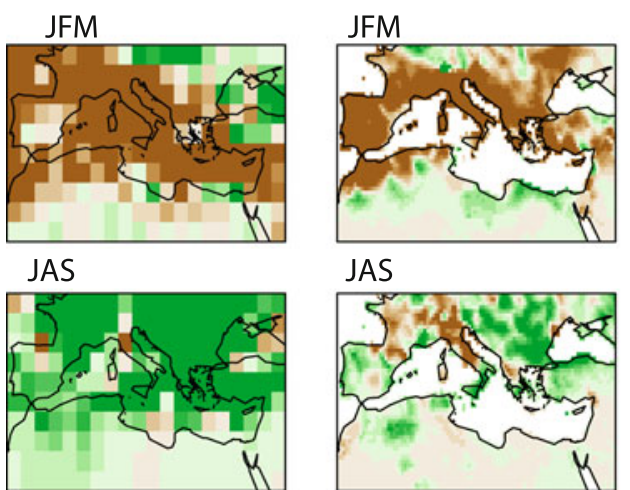

JAS

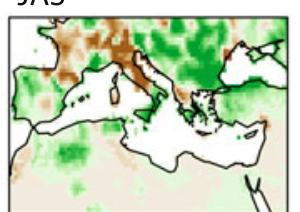

ASO

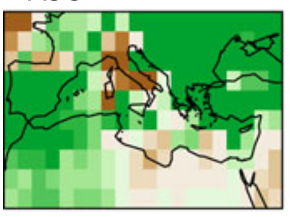

ASO
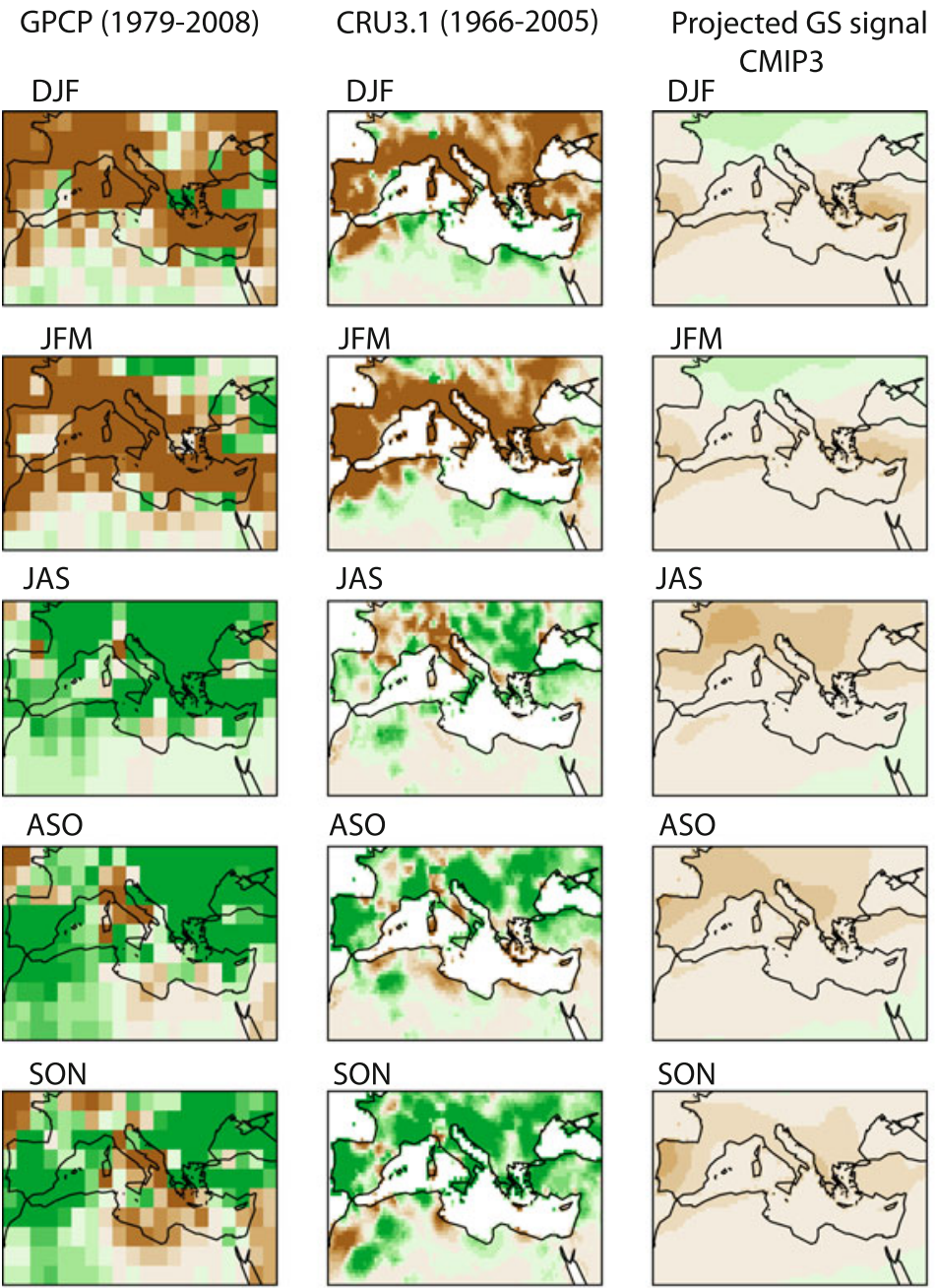

JAS

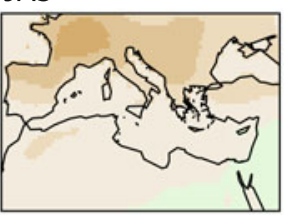

\section{ASO}
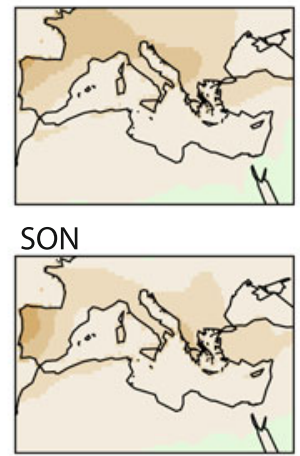

Projected GS signal INGV
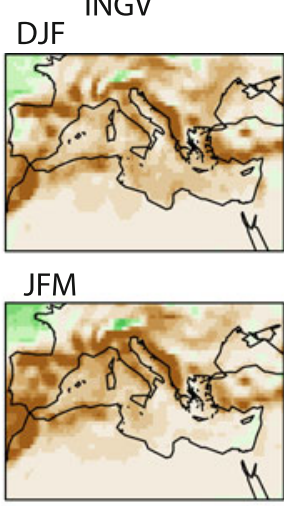

JAS

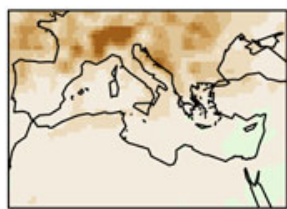

ASO

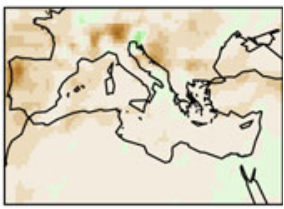

SON
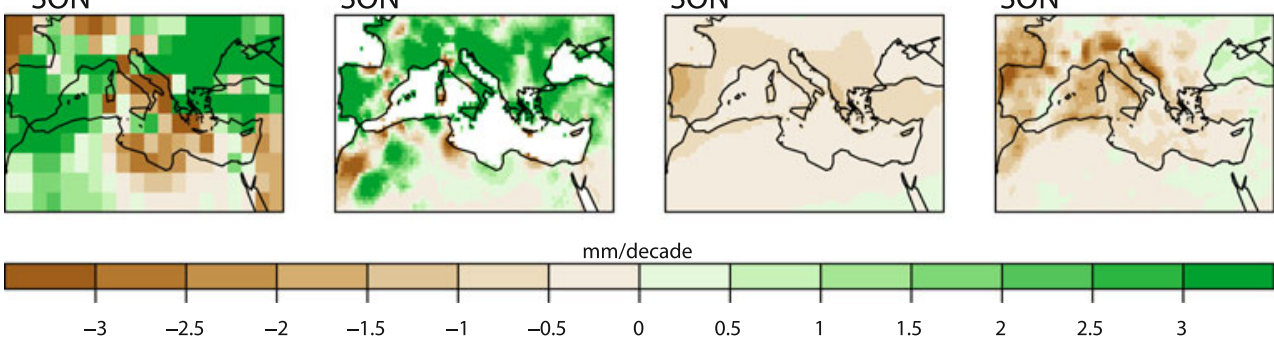

\subsection{Regression analysis}

In order to take the spatial pattern of changes into account, we further use regression indices (Eq. 1) and investigate whether the influence of anthropogenic forcing is detectable in observed changes that cannot be explained by natural (internal) variability alone.

Figure 4 shows the regression indices of observed precipitation changes according to GPCP dataset over the period 1979-2008 onto the GS signal patterns derived from 22 climate change projections in winter (DJF, JFM, FMA), late summer (JAS) and autumn (ASO and SON). As outlined in Sect. 3, the distribution of the regression indices are assessed from fits of the regression model (Eq. 1) to 285 independent control run segments derived from 9,000 year control simulations. The results of the regression analysis can be interpreted as follows: The GS forcing is detectable if the regression indices are significantly greater than zero, that is, the uncertainty range about the central estimate does not include the zero line. On the other hand, GS forcing is not detected if the indices are negative or not significantly greater than zero. Consistency of the observed trend patterns with the GS signal pattern is claimed in cases where the uncertainty range of regression indices dose not include zero but includes " 1 ".

In DJF, the $95 \%$ distribution of regression indices do not include the zero line with 8 out of the 22 models, indicating that the GS signal is detectable (on the $5 \%$ level) with 8 models. However, the uncertainty range does not include unity (except in two cases out of these 8 cases) and the central estimates of the regression indices are in the range of $[3.8,8.1]$, suggesting that while the effect of GS forcing is detectable in the observed record, these projections strongly underestimate the observed trends. In JFM the uncertainty range of regression indices does not include zero for 14 out of the 22 models, indicating that with 14 

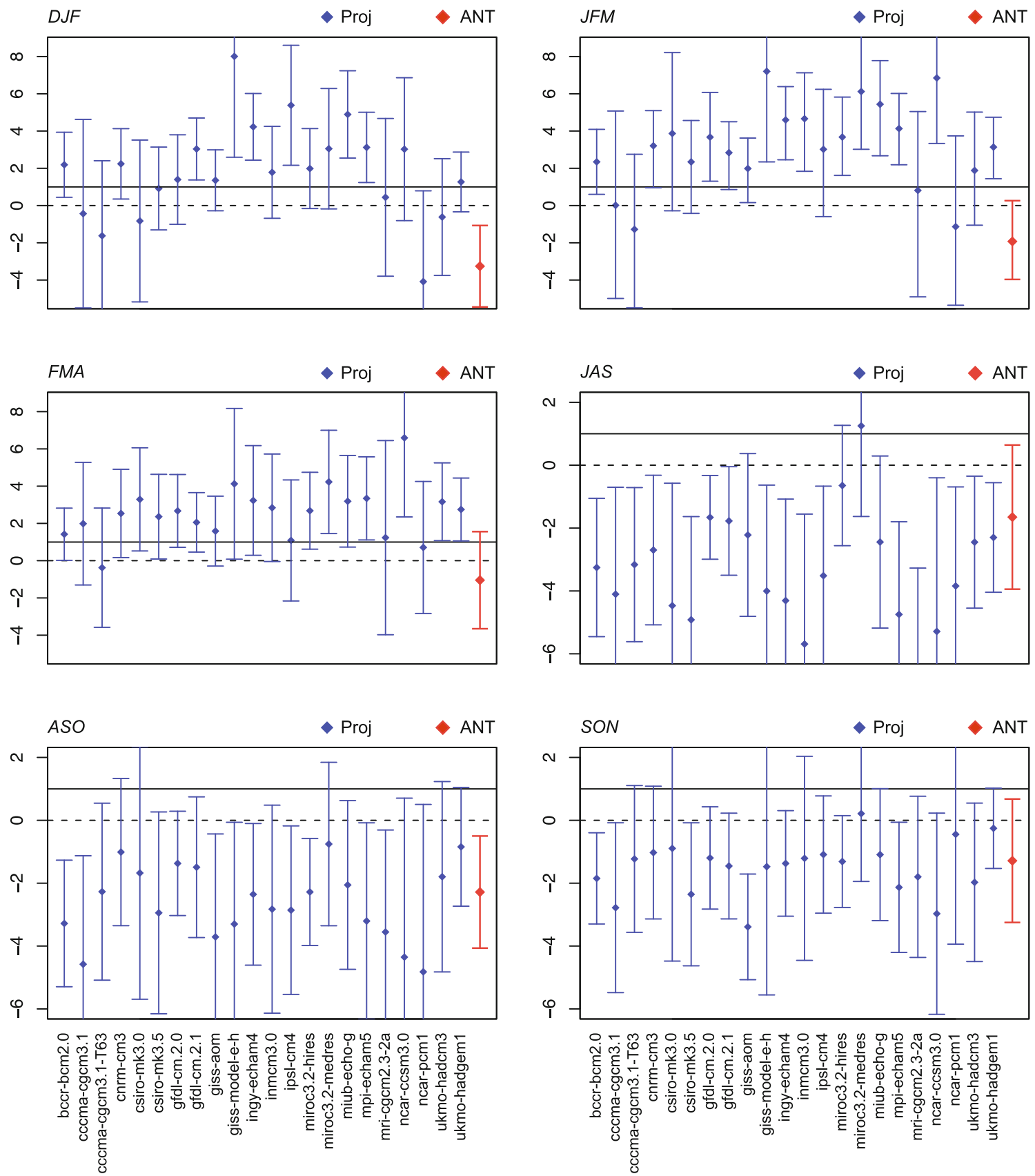

Fig. 4 Regression coefficients of observed precipitation change in DJF, JFM, FMA, JAS, ASO and SON from 1979-2008 according to the GPCP dataset on model simulated GS signal patterns. Blue GS signal patterns for 22 individual models estimated from time slices of climate projections based on the SRES A1B scenario. Red Regression against the multi-model ensemble mean of transient simulations with

anthropogenic forcing with 10 models (18 simulations) for the period from 1979 to 2008 . The bars show the $95 \%$ uncertainty range of the regression coefficients derived from model-based estimates of natural (internal) variability (285 non-overlapping 30-year segments derived from 9,000 years of control simulation). The solid lines mark regression coefficients equal to unity

models the GS signal is found to have a detectable influence on the observed record. Observed trend patterns, however, are inconsistent with the GS signal patterns, since climate change projections strongly underestimate the observed trends (the central estimate of regression indices of these 14 models is in the range of $[3.1,7.2])$. In FMA,

the GS signal is detectable with 14 out of 22 models, and for 9 out of these 14 models, the observed trend patterns are found to be consistent with GS signal patterns. In NDJ consistency is detectable solely with 3 out of 22 models (not-shown). In JAS, ASO and SON, the regression indices are negative with all 22 models except one model in JAS 
and one model in SON, indicating that the observations contradict the climate change projections, in agreement with results discussed in previous sections.

The red bars in Fig. 4 displays the regression of observed trend patterns onto the transient GS signal patterns as estimated from the multi-model mean of 10 models (18 ANT simulation). The negative regression indices in all intervals shown in Fig. 4, points to the inconsistency of observed precipitation changes with what models simulate as response of precipitation to GS forcing.

\section{Regionally detailed results}

The Mediterranean region is characterized by complex topographical and land-ocean features. The study by Gao et al. (2006) provides evidence that topography can induce fine scale features to the precipitation change signal over the Mediterranean region. To capture the fine scale structure of the climate change signal, we further use simulations with the INGV model (Gualdi et al. 2012). This model developed within the CIRCE EU-FP6 Project, consists of a high resolution general circulation model coupled to a high-resolution model of the Mediterranean Sea with a horizontal resolution of approximately $7 \mathrm{~km}$, which allow to assess the role of the basin, and in particular of the airsea feedbacks in the climate of the region (Gualdi et al.
2012). We use the time slice approach introduced in Sect. 1 to derive GS response patterns. Since the scenario run of INGV is only till 2070, the GS signal is defined as the difference of 2041-2070 and the reference climatology (1961-1990).

The INGV model, consistent with the suite of CMIP3 models, projects a negative trend in all sliding 3-month windows as a response to increasing GHG concentrations (Fig. 5). The precipitation change signals projected by the INGV model show seasonally dependent fine scale topographical detail over the Balkan mountains, Iberian Plateau, south of Turkey and North African coast lines. A noticeable feature is the horizontal gradient in precipitation change in DJF and JFM across the Alps with increases (or no changes) in precipitation at higher altitudes and large decreases in the low-lands (Fig. 3).

This topographycally-induced structure in the climate change signal is less evident in warm months, when convection rather than topographic uplift plays a major role (Gao et al. 2006). However, it is still evident in the JAS interval over the Alps (Fig. 3). The INGV model projects generally drier and warmer conditions in the region, with a maximum decrease in precipitation in winter (DJF, JFM) and a minimum decrease in summer (MJJ, JJA). The main part of the reduction is due to a decrease in the amount of convective precipitation in all months and snow fall in the cold months, while the decrease of large-scale precipitation

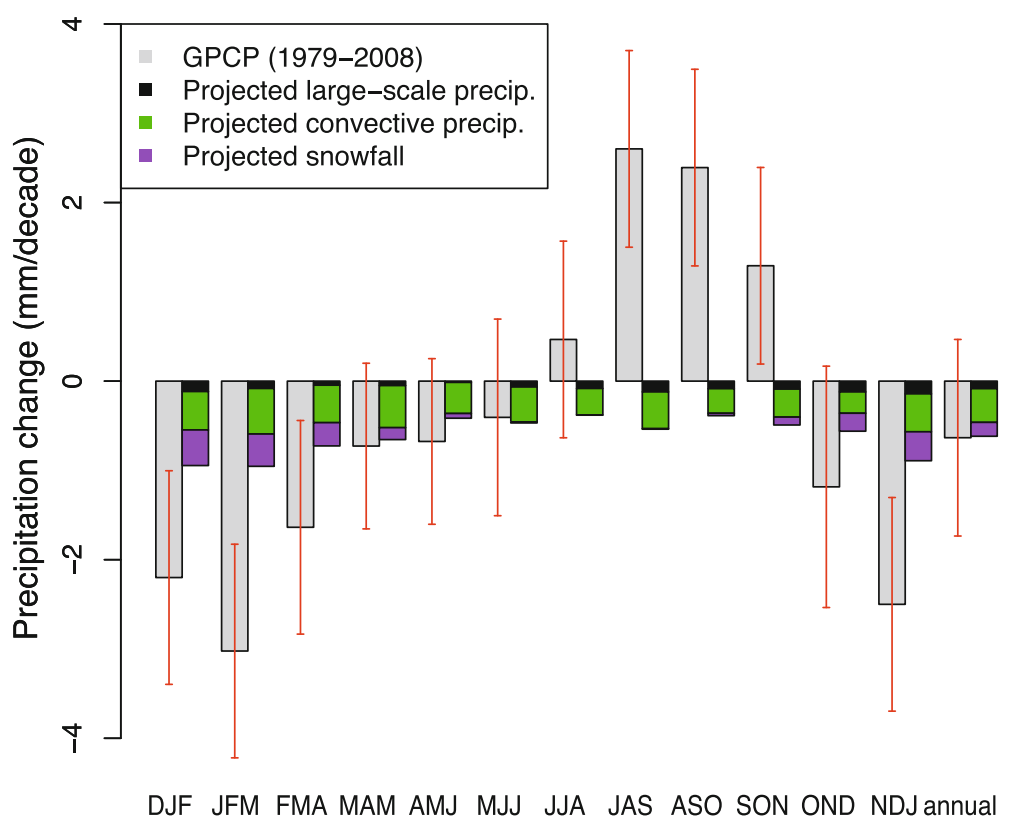

Fig. 5 Observed sliding 3-month window trends of precipitation over the land and sea of Mediterranean derived from GPCP dataset over the period from 1979 to 2008 (grey bars) in comparison with anthropogenic signals (GS) derived from INGV model (2041-2070 minus 1961-1990 mean scaled to change per decade). The vertical axes show area mean changes of precipitation ( $\mathrm{mm}$ per decade). The red whiskers indicate the $90 \%$ confidence interval of observed trends, derived from model-based estimate of internal (natural) variability. The black bars are projected large-scale precipitation; the green bars projected convective precipitation and the purple bars indicate projected snowfall 
plays only a minor role in the drought condition projected by the INGV model (Fig. 5).

The regression approach reveals that in winter (DJF, JFM and FMA) the anthropogenic signal (GS) is detectable over the 1979-2008 period (at the 5\% level, not shown). The GS signal, however, explains only a part of the observed drying, indicating that other processes likely also contribute. It is notable that the projected changes in winter in INGV are closer to the observations than trends estimated from the CMIP3 multi-model ensemble. This may point to the importance of using high resolution climate models in winter in order to generate the response to the topographic forcing, however, with the caveat of using just one model. Whereas in summer (JJA), in agreement with the suite of CMIP models, a strong inconsistency exists in both sign and intensity of the trends. This contradiction extends into autumn, in particular in JAS, ASO and SON, when observed trends are of opposite sign and more than 3 times larger than projected changes (Fig. 5).

\section{The influence of the NAO}

The North Atlantic atmospheric circulation and in particular the North Atlantic Oscillation (NAO Hurrell 1995) affects the Mediterranean climate (Lionello et al. 2006, and references therein). The positive phase of the NAO is associated with stronger surface westerlies across the midlatitudes and with anomalous northerly flow across the Mediterranean (Hurrell et al. 2003). Winter precipitation is anti-correlated with the NAO over most of the western Mediterranean region (Xoplaki 2002), southern Spain, and northern Morocco (Matti et al. 2009). This strong link is due to the control exerted by NAO on the branch of the storm track affecting the Mediterranean, mainly in its western part (Lionello et al. 2006). The NAO is also considered to be a key factor influencing the precipitation over the Mediterranean Sea, especially on decadal time scales (Mariotti and Dell'Aquila 2011).

It is now recognized that models may underestimate the variability of the North Atlantic Oscillation (Stephenson et al. 2006; Osborn 2004). The study by Gillett (2005) indicates that the simulated changes of the NAO in climate models are generally of correct sign but underestimate the magnitude of the observed changes. Underestimation of the simulated NAO variability may lead to a spurious detection result, if as a consequence the simulated natural variability is of smaller amplitude than the real variability. Therefore, in this section, we explore the consequences of subtracting from the observations that part of the precipitation variability that can be attributed to the NAO.

We use a station based NAO index (Osborn 2006). The fingerprint of the NAO is defined as the fraction of the variability in precipitation time series which co-varies with the NAO index. Thus, we define the fingerprint of the NAO as the slope of the regression of precipitation time series on the NAO index for each grid box separately. The NAO signal is removed from the observations by subtracting the product of the trend in the NAO index times the NAO signal from the trend in the observations.

Figure 6 shows the observed trends based on GPCP data for 1979-2008 in comparison with the observed trends after the removal of the NAO fingerprint. Statistical significance of the NAO-removed observed trends is determined using 9,000 years of control integrations and calculating 285 30-year segments for which the NAO
Fig. 6 Observed sliding 3-month window trends of precipitation over the land and the sea area of the

Mediterranean region in the time period from 1979 to 2008 (grey bars) in comparison with trends after the removal of the fingerprint of the NAO (green bars). The red whiskers indicate the $90 \%$ uncertainty range of observed trends, derived from model-based estimates of natural (internal) variability. The black whiskers denote the $90 \%$ uncertainty range of observed trends based on NAO-free internal variability (see Sect. 6)

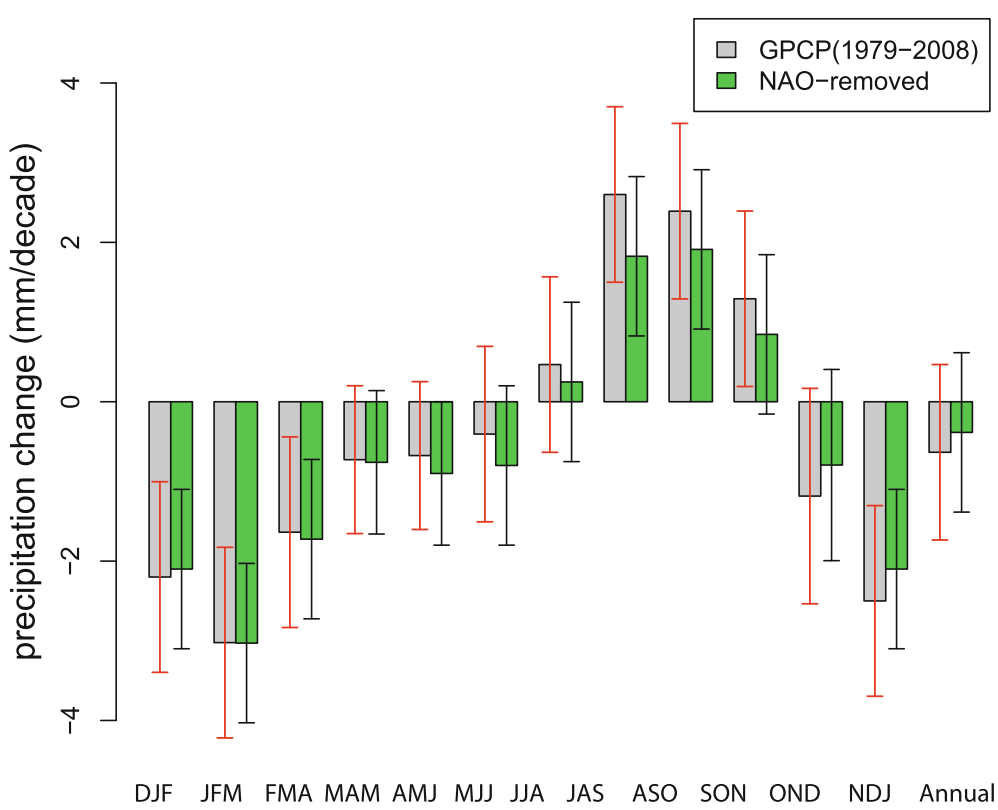


influence has been removed as well. The fingerprint of the NAO is removed from each of the 285 control run segments in a manner analogous to what was done with the observed record, that is, we regress the de-trended precipitation time series on the de-trended NAO index using ordinary least squares estimation of the parameters of the linear regression. The slope of the regression is the NAO fingerprint. Black whiskers in Fig. 6 denote the $90 \%$ uncertainty range of NAO-free internal variability.

The removal of the NAO signal does not considerably change the observed decreasing trend in winter (NDJ, DJF,
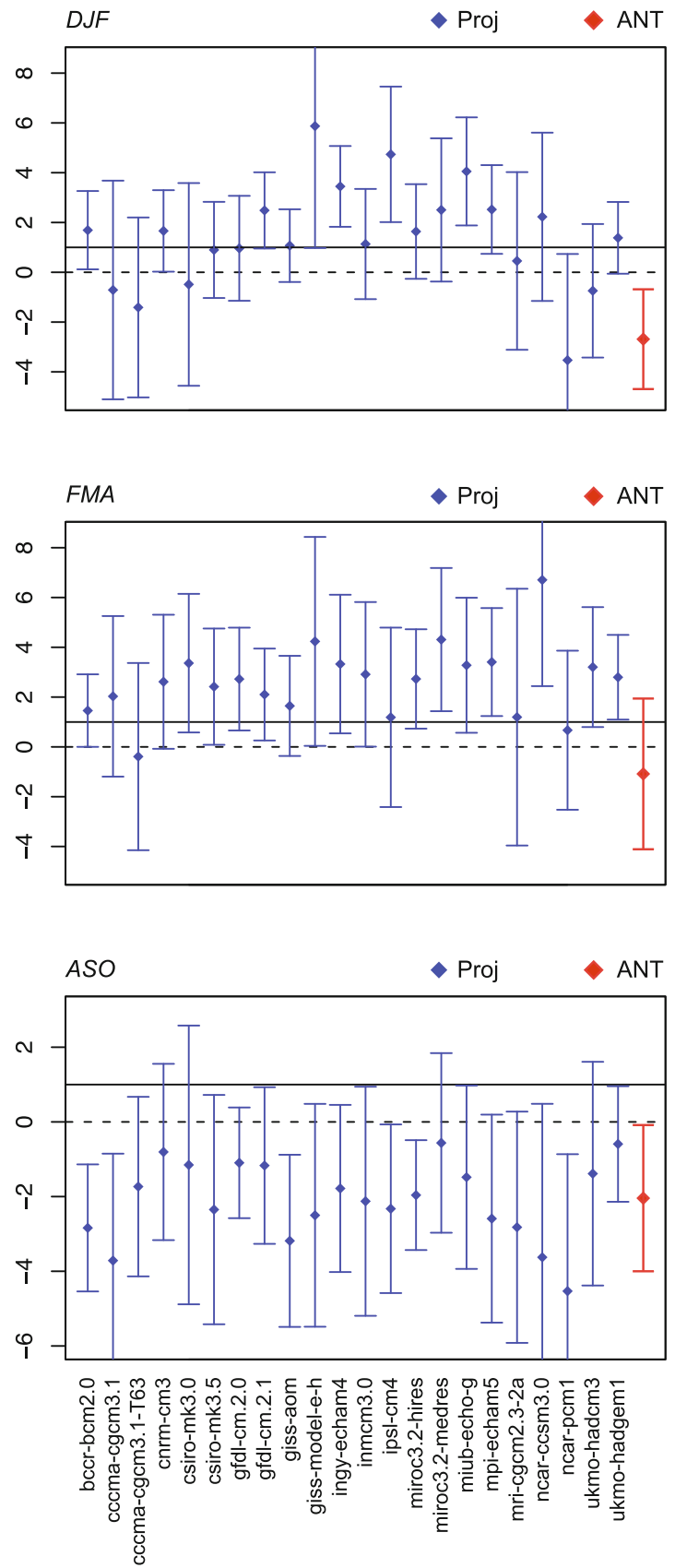

Fig. 7 Same as Fig. 4 but after the removal of the NAO fingerprint
JFM and FMA). The black whiskers in Fig. 6, do not include zero in winter, indicating that the residual trends can not be explained solely by NAO-free internal variability and that externally forced changes are detectable. Thus, a NAO index time series for 1979-2008 fails to exhibit trend-like behavior analogous to that seen for Mediterranean rainfall. Therefore, we conclude that the observed Mediterranean drying cannot be attributed to an observed change in the behavior of the NAO. These results are in line with the study by (Hoerling et al. 2012), who note that the NAO behavior has not changed in the
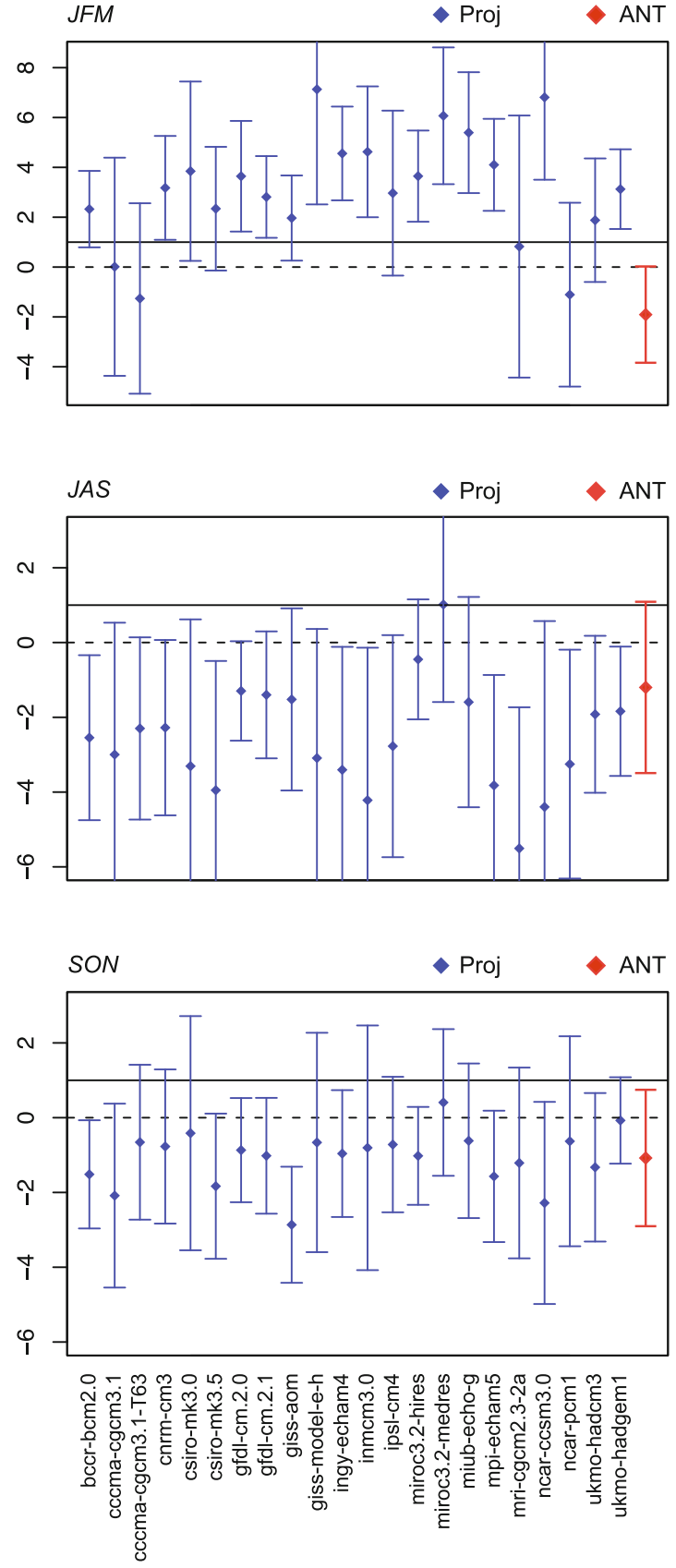
dramatic manner characterizing the temporal evolution (pre- and post-1970) of observed Mediterranean rainfall in the cold season (November-April).

Recently, a summer NAO manifestation has been shown to impact Mediterranean precipitation in this season (Folland et al. 2009). Our results also indicate that the NAO has been associated with approximately $50 \%$ of the observed rainfall increase in JJA, $34 \%$ in JAS, $23 \%$ in ASO and $41 \%$ in SON intervals. As indicated by the black whiskers in Fig. 6, none of the 285 NAO-free control run segments yield a positive trend as strong as that observed in JAS and ASO intervals. However, the detection of externally forced changes in observed precipitation trends in late summer (JAS) and autumn (ASO) and also the fact that observed positive trends contradict the climate change projections, are robust against the removal of the NAO signal.
Figure 7 displays the regression indices ( $y$ axis) of NAO-free observed precipitation changes onto climate change projections and its $95 \%$ uncertainty ranges, derived from NAO-free internal variabilty. Removing the effect of NAO causes a small reduction in the regression indices and slightly smaller uncertainty ranges. Thus, analysis of Fig. 7 further illustrates that the obtained results in Sect. 3 are robust against the removal of NAO fingerprint.

\section{Changes in large scale circulation}

In the Mediterranean region during winter, a strong correlation exists between the regional precipitation patterns and upper-air large-scale circulation anomalies (Quadrelli et al. 2001). The winter dryness over the eastern
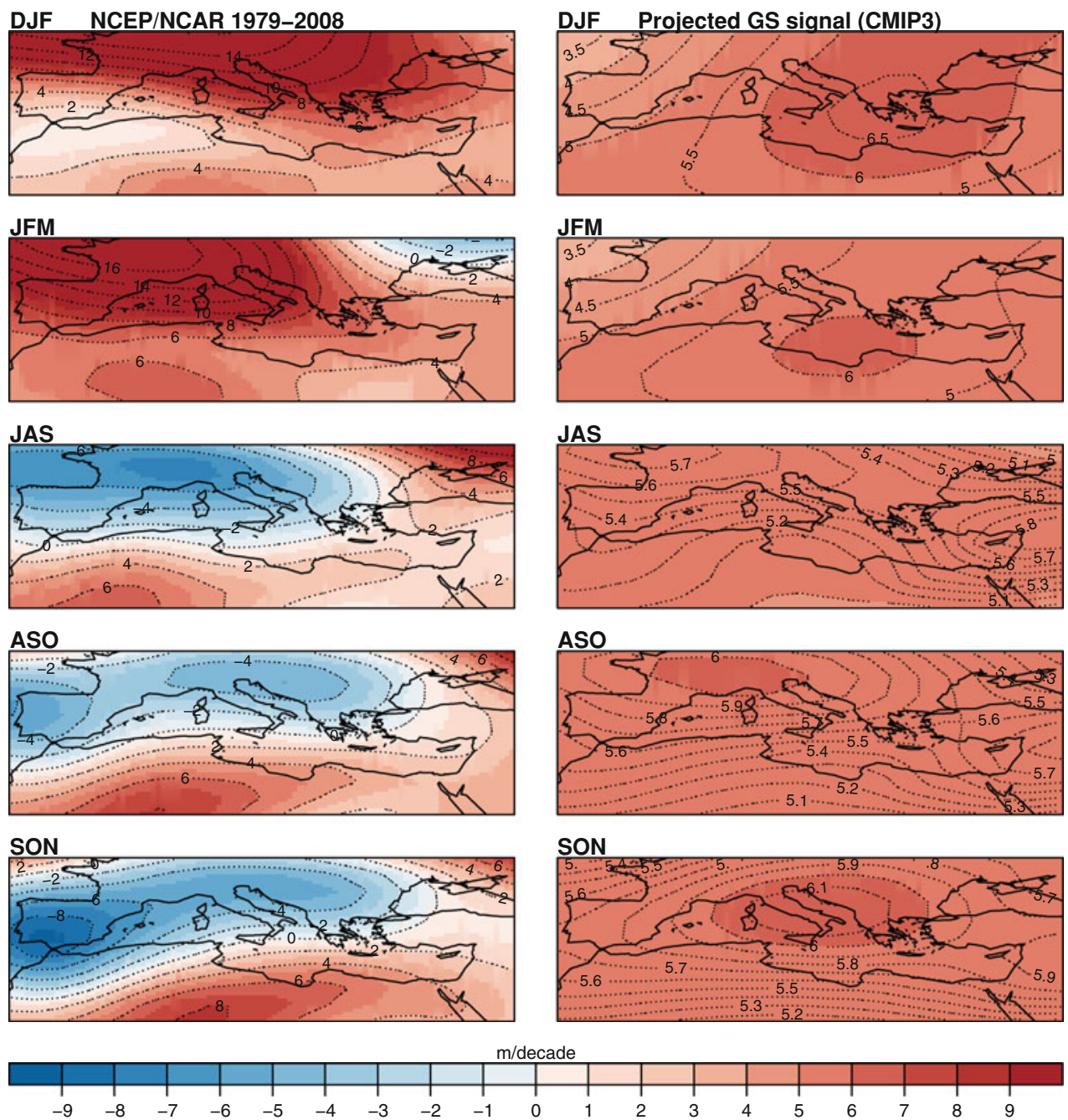

Fig. 8 Left column Observed patterns of change in 500 Gph according to the NCEP/NCAR reanalysis over the period 1979-2008 in winter (DJF and JFM), late summer (JAS) and autumn (ASO and SON). Right column Ensemble mean GS signal patterns estimated from time slices of climate projections from 22 models (2071-2100 minus 1961-1990 mean scaled to change per decade) according to the SRES A1B scenario 
Mediterranean (Greece) during 1958-1994 has also found to be connected with the raising of $500 \mathrm{hPa}$ geopotential height and increasing sea level pressure (Xoplaki et al. 2000). Over Europe, Haren et al. (2012) suggest that modeled atmospheric circulation and sea surface temperature (SST) trends over the past century contain large biases in global climate models and are responsible for a large part of the misrepresentation of precipitation trends over Europe in the CMIP3 climate models.

In this section, to examine the possibility that the inconsistency of observed precipitation trends with climate change projections may be related to trends in large-scale circulations, we compare observed (NCEP/NCAR reanalysis, Kalnay et al. 1996) and projected changes in geopotential height at $500 \mathrm{hPa}$ (referred to as $500 \mathrm{Gph}$ in the following), derived from the ensemble mean of the CMIP3 multi-model dataset (A1B scenario). The time slice experiment (Sect. 1) is used to estimate the trends of $500 \mathrm{Gph}$ in response to GS forcing. That is, we define the anthropogenic climate change signal (GS) of $500 \mathrm{Gph}$ as the difference between the last decades of the 21 st century (2071-2100, SRES A1B scenario) and the reference climatology (1961-1990). We assume a linear development in multi-decadal running means from 1961-2100 and the resulting signal is scaled to change per year. The linearity assumption is supported by the study of Cubasch et al. (2001) who indicates that the global mean response to anthropogenic forcing is as a first approximation linear. Natural (internal) variability of $500 \mathrm{Gph}$ is estimated from long control simulations. As outlined in Sect. 3, we draw 285 independent segments with the same length and spatial coverage as the observations (NCEP reanalysis) from 9,000 years of control simulations to estimate the internal variability of 30-year trends of $500 \mathrm{Gph}$ in an undisturbed stationary climate.

Figure 8 shows the $500 \mathrm{Gph}$ trend patterns in NCEP/ NCAR over the period 1979-2008 in DJF, JFM, JAS, ASO and SON, in comparison with what the ensemble mean of 22 models projects as a response of $500 \mathrm{Gph}$ to GS forcing. Using an ensemble mean of 22 models (49 simulations), leads to decreasing the internal variability by more than $90 \%$ in the response pattern.

In winter (DJF and JFM), trends in the NCEP reanalysis data show a tendency towards a ridge that covers a large part of the Mediterranean. The increase in $500 \mathrm{Gph}$ (and also the sea level pressure, not shown) over the region thus enhance atmospheric stability. The anticyclonic circulation and the decrease in the occurrence of convection due to increasing subsidence thus lead to the winter dryness over the region. The response of $500 \mathrm{Gph}$ to GS forcing is also characterized by a monopole pattern, however in terms of magnitude of change, the CMIP3 climate change projections show an uniform increase (Fig. 8) and underestimate the observed increasing trend of up to $16 \mathrm{~m} / \mathrm{decade}$, which consequently may lead to an underestimation of the observed deceasing trend in the amount of precipitation.

Figure 9 shows the area-mean changes of $500 \mathrm{Gph}$ in the NCEP/NCAR reanalysis data in DJF, JFM, FMA,JAS, ASO, and SON along with the respective $95 \%$ uncertainty range due to internal variability (red whiskers in Fig. 9) derived from long control simulations (outlined in Sect. 3). In the winter months, the NCEP/NCAR reanalysis data suggests a $5.8 \mathrm{~m} /$ decade increase of $500 \mathrm{Gph}$ in DJF, $6.8 \mathrm{~m} /$ decade increase in $\mathrm{JFM}$ and $6.3 \mathrm{~m} /$ decade increase in FMA (Fig. 9). These observed changes are found to be different from changes due to natural (internal) variability alone (as indicated by the red whiskers in Fig. 9), whereas they are within the range of changes suggested by 22 climate change scenarios (black whiskers in Fig. 9). Projected changes derived from 22 models are in the range of [3.2-13] $\mathrm{m} /$ decade, [3.4-13.6] $\mathrm{m} /$ decade, and [3.7-13.3] $\mathrm{m} /$ decade in DJF, JFM and FMA, respectively. Lucarini and Russell (2002) also show a significant positive trend of $500 \mathrm{Gph}$ (almost $6 \mathrm{~m} /$ decade) in winter (DJF) with NCEP/ NCAR over the period 1960-2000, which is underestimated by GHG experiments.

In contrast to the situation in winter, in late summer (JAS), the NCEP/NCAR reanalysis data shows an area of decreasing geopotential height $(-5 \mathrm{~m} / \mathrm{decde})$, and thus increasing cyclonic circulation over the north and northwest of the Mediterranean and an area of increasing geopotential height $(+6 \mathrm{~m} /$ decade) in the south (Fig. 8$)$. This dipole mode portrays northward migration of storm tracks. The same dipole structure is also observed in ASO and SON intervals, when a cyclonic circulation is observed over the northwest of the region with a $-9 \mathrm{~m} / \mathrm{decade}$ decreasing trend in $500 \mathrm{Gph}$, and an anticyclonic circulation over the south with $+8 \mathrm{~m} /$ decade increasing trend of $500 \mathrm{Gph}$. This results in a blocking-like pattern in autumn that tends to deflect storms northward. Furthermore, the areas of lower pressure tend to result in an increase in the occurrence of convection. Thus, the corresponding changes in the storm track favour an increase in late summer and autumn precipitation over the north and north-west of the Mediterranean area.

As shown in Fig. 8 (right column), the projected $500 \mathrm{Gph}$ change pattern in late summer and autumn is strikingly inconsistent with changes in the NCEP/NCAR reanalysis data over the 1979-2008 period. The CMIP3 models project changes towards more anticyclonic conditions over the Mediterranean. The projections also show an upward trend in mean sea level pressure (not shown). Increasing pressure and anticyclonic conditions go along with less rain, which is at odds with the observed significant positive trends in the amount of precipitation in late summer and autumn. When comparing the area-mean 
Fig. 9 Seasonal area mean changes of observed $500 \mathrm{Gph}$ (in $\mathrm{m} /$ decade) according to the NCEP/NCAR reanalysis over the period 1979-2008 (grey bars) in comparison with the anthropogenic signal (GS) of $500 \mathrm{Gph}$ derived from the multi-model mean of CMIP3 simulations according to the SRES A1B scenario. The black whiskers indicate the spread of trends of the 22 climate change projections. The red whiskers denote the $95 \%$ uncertainty range of observed trends derived from long control simulations

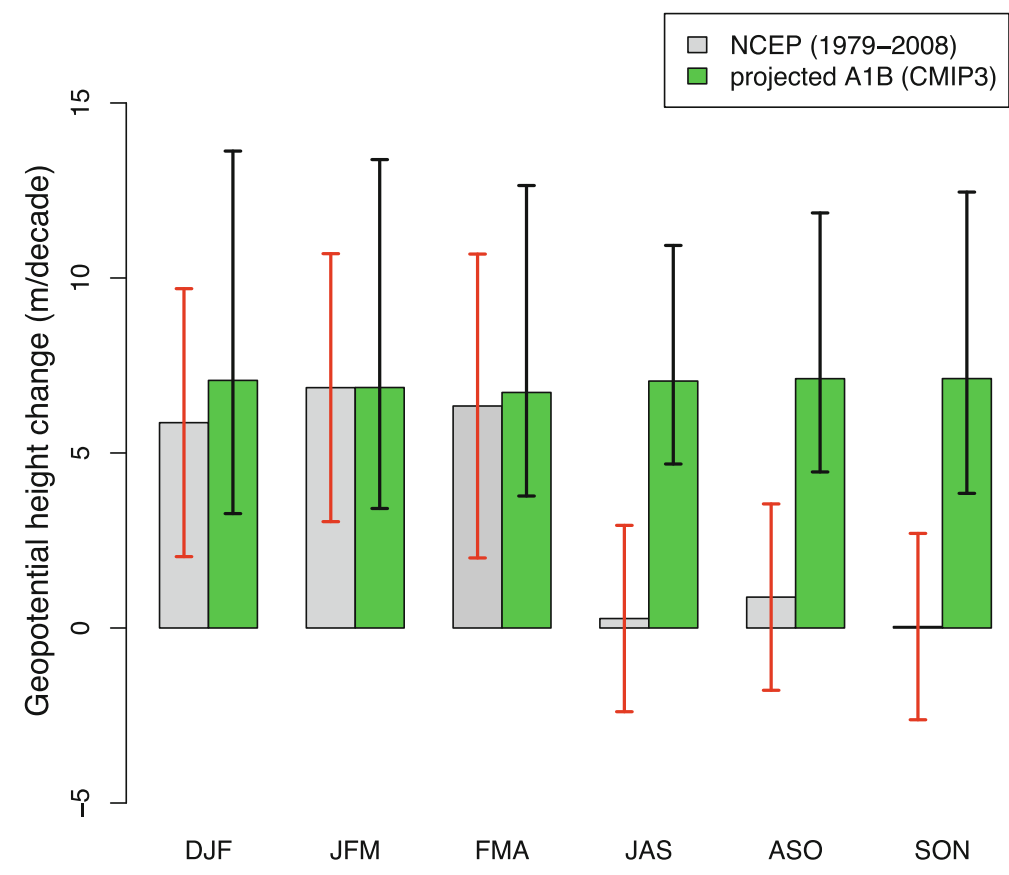

GS forcing derived from the multi-model ensembles mean of 22 models. The $95 \%$ distribution of regression indices are assessed by calculating regression indices of 285 nonoverlapping control run segments on the GS signal patterns. In winter and early spring (DJF, JFM and FMA), the uncertainty range of regression indices does not include "zero" but includes "1" (Fig. 10). This indicates that the GS signal is detectable in the NCEP/NCAR reanalysis data over the 1979-2008 period and anthropogenic forcing is a plausible explanation for observed positive trends of $500 \mathrm{Gph}$ in winter and spring (with less than $5 \%$ risk level). In contrast to winter and spring, the regression indices are almost zero in JAS, ASO and SON, indicating the inconsistency of observed trends of $500 \mathrm{Gph}$ with climate change projections.

Therefore, we conclude that it is-at least to some extent-the inconsistency of the description of ongoing changes in circulation in the simulated possible futures, which leads to the inconsistency with observed precipitation trends in late summer and autumn. The mismatch between simulated and observed precipitation in late summer and autumn is already present in the atmospheric circulation.

\section{Dependence on trend period}

We further analyze how strongly our results depend on the exact time period under analysis. Figure 11 shows moving 40-year trends in CRU3.1 and GPCC5 over the time period from 1901 to 2009. The CRU3.1 and GPCC5 observed records exhibit strong disagreement during the early migure 10 displays the regression coefficients observed $500 \mathrm{Gph}$ changes against changes in response to 
decades. This is probably related to sparse data coverage during the 1900-1960 period (not shown) and differences in the treatment of data-sparse areas in the different datasets. However, after 1960 the two datasets come to a relatively good agreement. The observed trends are likely not due to internal variability alone in cases for which the trend is beyond the 5-95\% distribution of 213 control run segments (as denoted by the horizontal dashed lines in Fig. 11).

In winter (DJF, JFM), both datasets show developing drought conditions towards the end of the 20th century. The observed trends in winter months become significantly different from internal variability in the early 1990s, with strongest drying during 1960-2000 in JFM with about $-2.8 \mathrm{~mm} /$ decade decrease in the amount of precipitation. There is indication of a slight decrease in the strong drying in the 21 st century. In spring and summer (MJJ, JJA, JAS) in contrast, the observed trends are hardly distinguishable from unforced trends and externally forced changes are not detectable. In late summer and autumn (ASO, SON and OND), both datasets show a period with increasing precipitation over the Mediterranean after the 1960s (40-year trends ending in the late 1990s), which contrast mostly

Fig. 11 Seasonal moving 40-year observed trends based on CRU3.1 (red curves) and GPCC5 (blue curves) from 1901 to 2009 . The vertical axes denote the area mean change of precipitation over the Mediterranean region. The horizontal axes show the endyear of moving 40-year trends. The dotted horizontal lines indicate the 5-95\% uncertainty range of observed trends, derived from model-based estimates of natural (internal) variability (213 independent 40-year segments derived from 9,000 years of control simulations)
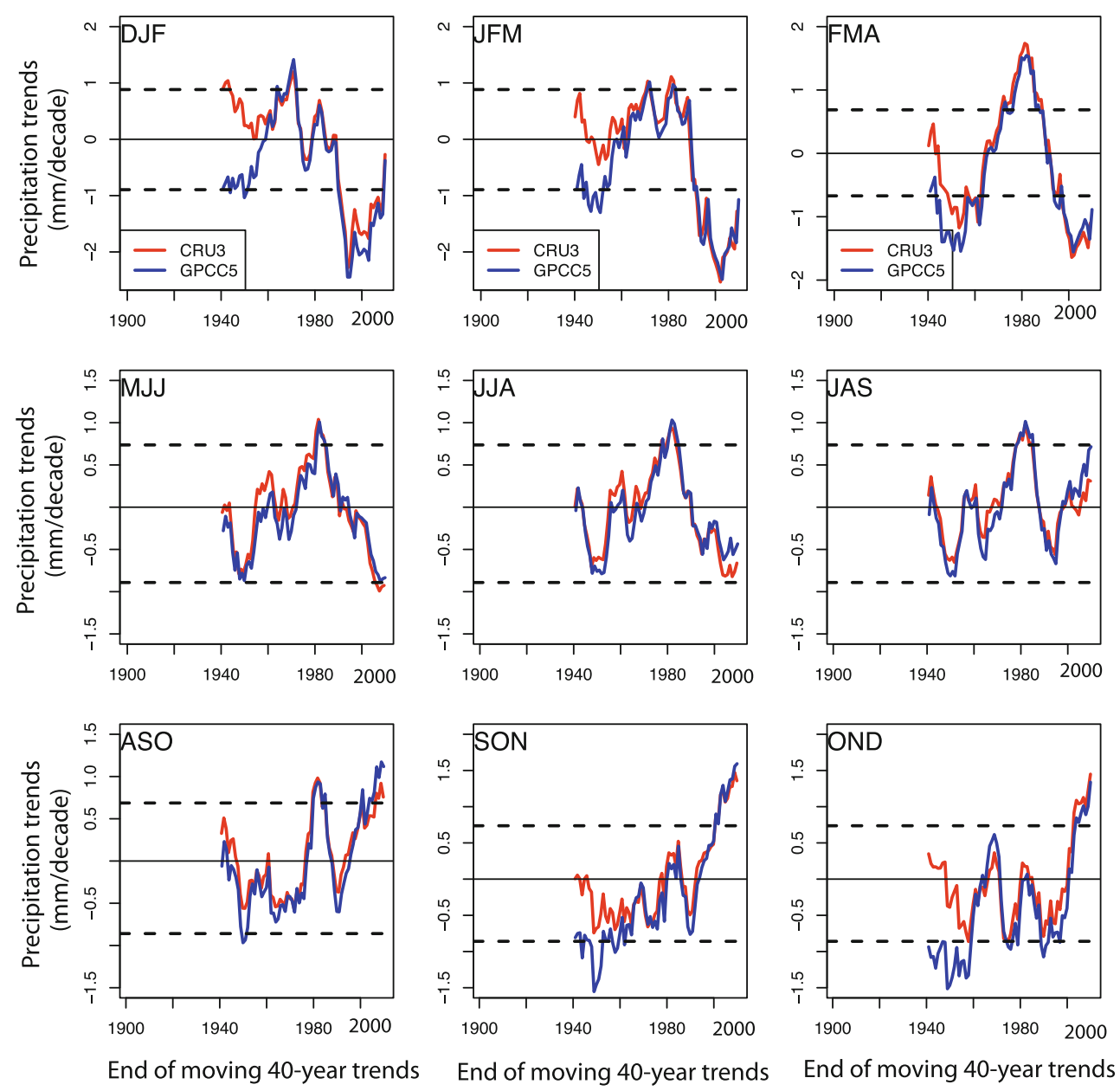
Fig. 12 Seasonal regression indices of observed moving 40-year trends, over the period 1901-2009, based on CRU3.1 onto the multi-model mean GS signal, estimated from two wellseparated time slices (2071-2100 minus 1961-1990 mean scaled to change per decade, A1B scenario) ensemble mean of 22 models from CMIP3 archive. The vertical axes denote the regression indices. The horizontal axes show the endyear of moving 40-year trends. The grey shaded area indicates the $95 \%$ range of regression indices in a stationary climate derived from 213 nonoverlapping control run segments. The dotted lines mark regression indices equal to zero, and the solid lines mark regression indices equal to unity
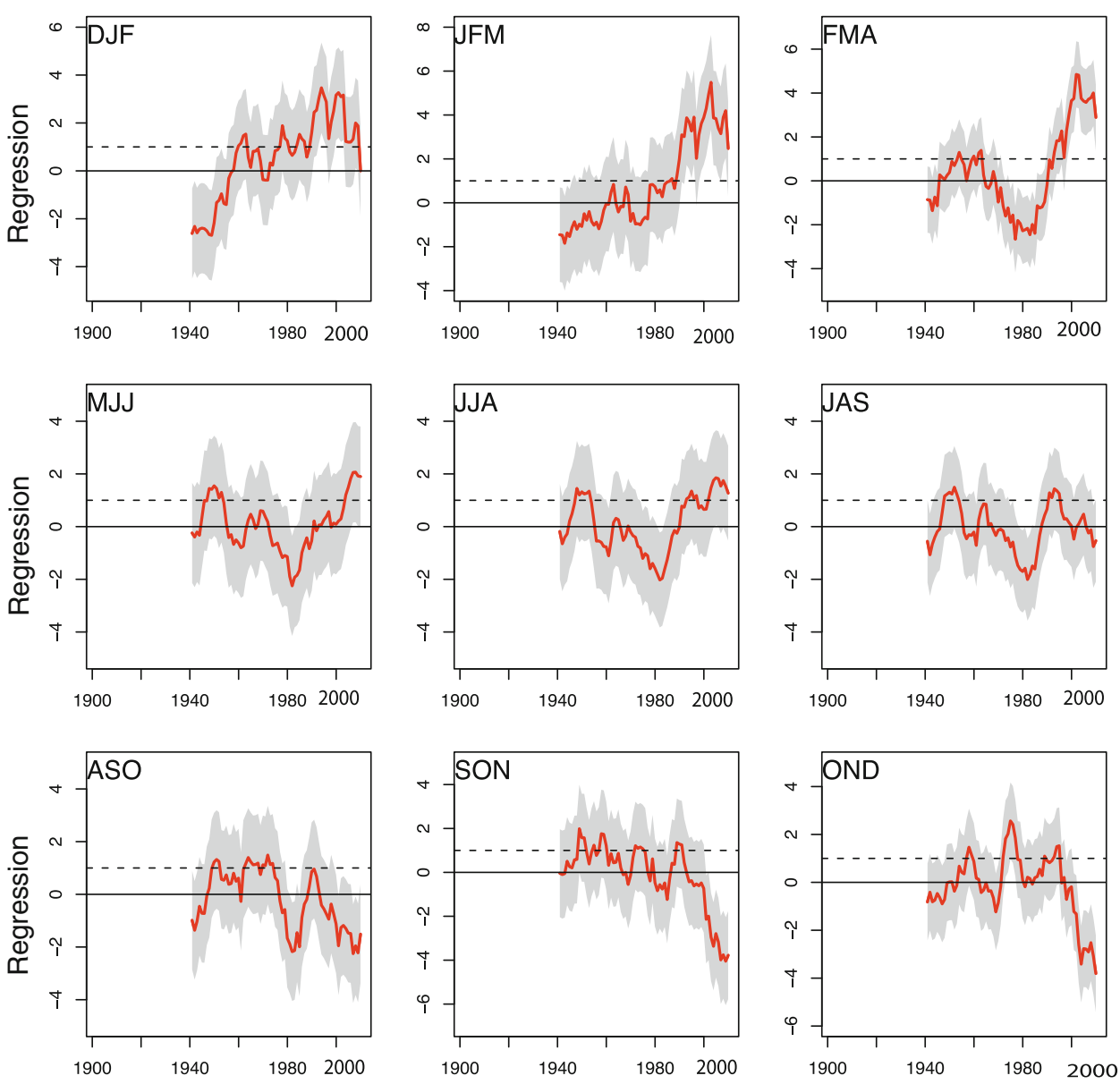

End of moving 40-year trends
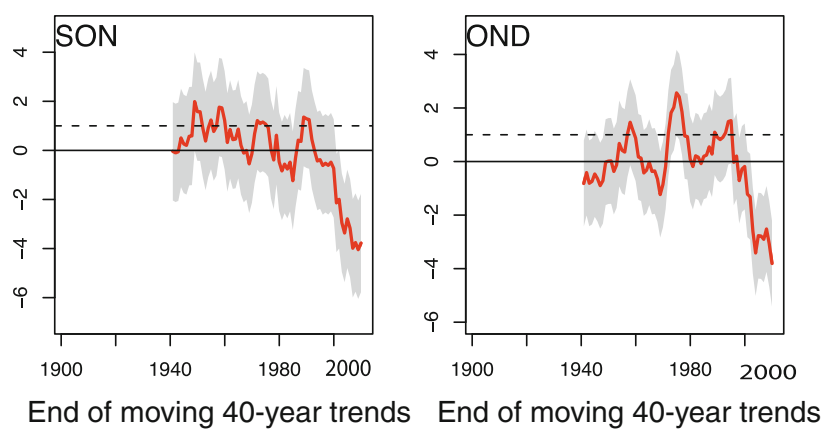

(GS) influence in the late 20th century. While the influence of GS signal is detectable, the gray shaded area clearly does not include 1 in FMA (and to a lesser extent in JFM and DJF), indicating that the climate change projections underestimate the observed trends.

In ASO, SON and OND, the detection of an outright sign mismatch of observed and projected trends is obvious with negative regression indices of 40-year trends ending in 1990 and later on. The negative regression indices in SON and OND become significantly beyond the range of regression indices of unforced trends with GS signal patterns in the late 20th century. This result points either to the presence of an alternative driver of precipitation change not included in the models or to gross misrepresentation of the precipitation response to GS forcing in the CMIP3 simulations.

\section{Conclusion}

In this study, we examine to what extent the present climate change "is on the way" towards conditions described by the climate change scenarios at the end of this century.
To this end, we determine if the observed trends in precipitation over the period 1966-2005 (over land) and 1979-2008 (over land and sea), are consistent with the expected change due to GS forcing. Our analysis demonstrates that externally forced changes are detectable (at the $5 \%$ level) in observed precipitation trends in winter, late summer and in autumn. Natural (internal) climate variability cannot explain these changes. In contrast, we do not find evidence for the presence of an external driving factor in the observed precipitation trends in spring and early summer. In addition, we show that the observed trends (derived from 3 sources) are markedly inconsistent with expected changes due to GS forcing. While the influence of GS forcing is detectable (at the $5 \%$ level) with 8 out of 22 models in DJF, 14 models in JFM and 14 models in FMA, observed changes are several times larger than the projected response to GS forcing in these models. The most striking inconsistency, however, is the contradiction between projected drying and the observed increase in precipitation in late summer and autumn. Our analysis thus points to the presence of an external forcing which is in contrast to the expected response to GS forcing. The inconsistency of observed trend patterns with GS signal 
patterns in winter, late summer and autumn are robust against the approach used to estimate the GS response and are also robust against estimating the GS signal from a high resolution climate model (INGV). The results are furthermore insensitive to the removal of the fingerprint of the North Atlantic Oscillation.

Analysis of changes in large scale circulation patterns reveals that the influence of GS forcing is detectable in the observed (NCEP/NCAR reanalysis) $500 \mathrm{Gph}$ in winter (DJF, JFM) and spring (FMA, MAM, AMJ). The observed positive trends of $500 \mathrm{Gph}$ are consistent with the ensemble mean of 22 climate change projections. However, in late summer (JAS) and autumn (ASO, SON) the observed dipole pattern of $500 \mathrm{Gph}$ contradicts the uniform increase pattern of $500 \mathrm{Gph}$ projected by CMIP3 models. This indicates that inconsistencies in the simulated circulation response could account for at least some of the inconsistencies between simulated and observed precipitation changes in the Mediterranean. Our analysis clearly shows that projections of future regional precipitation change, an important factor for the estimation of future agricultural and hydrological resources, are not consistent with observed recent changes. We note that our results must be interpreted with the caveat of potential inhomogeneity in the observed gridded precipitation data sets. Another caveat is the coarse horizontal resolution of the climate models used in this study.

Candidates to explain the observed inconsistency are manifold and we will highlight the most important ones. Careful analysis of the potential sources for inconsistency, however, is beyond the scope of this manuscript. First, natural internal variability could be much stronger than simulated. Observed variability of changes in the NAOan important indicator of circulation variability in the region-has been found to exceed simulated variability (Gillett 2005). Our conclusions, however, are insensitive to a potential underestimate of NAO-related variability in the models.

Second, changing atmospheric greenhouse gas and sulfate concentrations are not the dominant forcing for precipitation changes in the Mediterranean region. Previous studies conclude that global precipitation changes are more sensitive to short-wave forcing such as changes in stratospheric aerosol concentrations due to explosive volcanic eruptions than low-frequency GHG forcing (Lambert et al. 2004). This is in contrast to global land temperature anomalies, which are dominated by the response to GHG forcing (e.g., Stott et al. 2000). Furthermore, there are additional anthropogenic forcing agents which potentially have a large effect on regional scale precipitation and which are missing in current climate models such as the emission of aerosols related to traffic and industry and/or forcing from land-use changes such as deforestation.
Whether the inconsistency of observed and simulated precipitation changes might be resolved taking into account additional forcing mechanisms could be assessed with the next generation of climate models that include a more complete set of processes relevant for precipitation formation (CMIP5 Taylor et al. 2012).

Third, the inconsistency could also be due the misrepresentation of the precipitation response to GS forcing in the CMIP3 models. The good model agreement on the forced response (e.g. Figs. 1, 2) suggests, however, that this is a valid explanation only if all of the CMIP3 models misrepresent the GS response. Furthermore, it has been suggested that sea surface temperature (SST) forcing likely played an important role in the observed Mediterranean wintertime drying (Hoerling et al. 2012). The CMIP3 models have biases in their SST response to GHG forcing, especially over the tropical Pacific (Vecchi et al. 2008). Our results indicate that the CMIP3 models simulate a relatively uniform increase in $500 \mathrm{Gph}$ in response to anthropogenic forcing (Fig. 8). The CMIP3 models also simulate a uniform pattern of SST change in response to anthropogenic forcing. The observed change in tropical SSTs, however, involves a stronger zonal SST gradient across the Indian and Pacific Ocean than simulated in CMIP3 models (Hoerling et al. 2012). Thus, it is suggested by Hoerling et al. (2012) that the amplitude of the CMIP3 drying signal in winter (November-April) over the Mediterranean is weak owing to biases in the coupled model's global SST response.

Overall, communication of future expected change of precipitation is complicated by the fact that the expected future changes are inconsistent with observed changes, irrespective of the data sets used. We have earlier determined that the ongoing trends in temperature in the Mediterranean region are consistent with climate change projections (Barkhordarian et al. 2012). Therefore, recently observed warming is a plausible illustration of future expected warming in the region. In terms of precipitation, the detection of an outright sign-reversal in the observed and projected trends, which is a newly documented phenomenon, provides strong evidence that the recent observed changes cannot be used to illustrate the future expected changes of precipitation. The societal significance of our analysis is in the answer of the often-asked question in the public: Is the recent trend a harbinger of the future? In the case of precipitation, in the Mediterranean region: quite probably not.

Acknowledgments A.B. was funded by CIRCE EU-FP6 integrated project. We appreciate Eduardo Zorita and two anonymous reviewers for their valuable and constructive comments on the manuscript. The Climate Research Unit has provided the CRU data set. The GPCC5 observations have been provided by the Global Precipitation Climatology Centre operated by National Meteorology Service of Germany 
(DWD). We further acknowledge the modelling groups, the Program for Climate Model Diagnosis and Intercomparision (PCMI) and the WCRPs Working Group on Coupled Modelling (WGCM) for their roles in making available the WCRP CMIP3 multi-model dataset. The office of Sciences, U.S. Department of Energy, provides support of this dataset. The GPCP has been provided by Global Energy and Water Cycle Experiment (GEWEX) of the World Climate Research Programme (WCRP). We acknowledge the International Detection and Attribution Group (IDAG). NCEP Reanalysis data is provided by the NOAA/OAR/ESRL PSD, Boulder, Colorado, USA. We thank Silvio Gualdi for INGV model data produced within the CIRCE EUFP6 integrated Project.

Open Access This article is distributed under the terms of the Creative Commons Attribution License which permits any use, distribution, and reproduction in any medium, provided the original author(s) and the source are credited.

\section{References}

Adler RF et al (2003) The version 2 Global Precipitation Climatology Project (GPCP) monthly precipitation analysis (1979-Present). J Hydrometeor 4:1147-1167

Allen MR, Tett SFB (1999) Checking for model consistency in optimal fingerprinting. Clim Dyn 15:419-434

Arblaster et al. (2011) Future climate change in the Southern Hemisphere: competing effects of ozone and greenhouse gases. Geophys Res Lett 38:L02701

Barkhordarian A, Bhend J, von Storch H (2012) Consistency of observed near surface temperature trends with climate change projections over the Mediterranean region. Clim Dyn 38: $1695-1702$

Barkhordarian A (2012) Investigating the influence of anthropogenic forcing on observed mean and extreme sea level pressure trends over the Mediterranean region. Sci World J. doi:10.1100/ 2012/525303

Barkhordarian A, von Storch H, Zorita E Anthropogenic forcing is a plausible explanation for the observed surface specific humidity trends over the Mediterranean area (Submitted for publication)

Bhend J, von Storch H (2008) Consistency of observed winter precipitation trends in northern Europe with regional climate change projections. Clim Dyn 31:17-28

Christensen JH et al. (2007) Regional climate projections. In: Solomon S et al (eds) Climate Change 2007: The physical science basis. Contribution of Working Group I to the Fourth Assessment Report of the Intergovernmental Panel on Climate Change. Cambridge University Press, Cambridge

Cubasch U, Meehl G, Boer G, Stouffer R, Dix M, Noda A, Senior C, Raper S, Yap K (2001) Projections of future climate change. In: Houghton J, Ding Y, Griggs D, Noguer M, Linden P, Dai X, Maskell K, Johnson C (eds) Climate change 2007: the physical science basis. Contribution of Working Group I to the third assessment report of the Intergovernmental Panel on Climate Change. Cambridge University Press, Cambridge, pp 99-181

Deque $M$ et al (2005) Global high resolution versus Limited Area Model climate change projections over Europe: quantifying confidence level from PRUDENCE results. Clim Dyn 25:653-670

Easterling DR, Peterson TC (1995) A new method for detecting undocumented discontinuities in climatological time-series. Int J Clim 15:369-377

Folland CK, Knight J, Linderholm HW, Fereday D, Ineson S, Hurrell JW (2009) The Summer North Atlantic oscillation: past, present, and future. J Clim 22:1082-1103
Gao XJ, Pal JS, Giorgi F (2006) Increased aridity in the Mediterranean region under greenhouse gas forcing estimated from highresolution simulations with a regional climate model. Geophys Res Lett 33:L03706

Gao XJ, Giorgi F (2008) Increased aridity in the Mediterranean region under greenhouse gas forcing estimated from high-resolution simulations with a regional climate model. Glob Planet Change 62:195-209

Giorgi F (2006) Climate change hot-spots. Geophy Res Lett 33:L08707

Giorgi F, Lionello P (2008) Climate change projections for the Mediterranean region. Glob Planet Change 63:90-104

Gillett NP, Zwiers FW, Weaver AJ, Hegerl GC, Allen MR, Stott PA (2002) Detecting anthropogenic influence with a multi-model ensemble. J Geophys Res 29:015836

Gillett NP, Weaver AJ, Zwiers FW, Wehner MF (2004) Detection of volcanic influence on global precipitation. Geophys Res Lett 31:L12217

Gillett NP (2005) Climate modelling-Northern Hemisphere circulation. Nature 437:496

Giorgi $F$ et al (2001) Emerging patterns of simulated regional climatic changes for the 21 st century due to anthropogenic forcing. Geophys Res Lett 28:3317-3320

Giorgi F, Bi X (2005) Updated regional precipitation and temperature changes for the 21 st century from ensembles of recent AOGCM simulations. Geophys Res Lett 32:L21715

Gualdi S, Somot S, Li L, Artale V, Adani M, Bellucci A, Braun A, Calmanti S, Carillo A, Dell'Aquila A, Dqu M, Dubois C, Elizalde A, Harzallah A, Jacob D, L'Hvder B, May W, Oddo P, Ruti P, Sanna A, Sannino G, Scoccimarro E, Sevault F, Navarra A (2012) The CIRCE simulations: a new set of regional climate change projections performed with a realistic representation of the Mediterranean Sea. Bull Amer Meteor Soc. doi: 10.1175/BAMS-D-11-00136.1

Haren R van, van Oldenborgh GJ, Lenderink G, Collins M, Hazeleger W (2012) SST and circulation trend biases cause an underestimation of European precipitation trends. Clim Dyn. doi: 10.1007/s00382-012-1401-5

Hegerl GC, vonStorch H, Hasselmann K, Santer BD, Cubasch U, Jones PD (1996) Detecting greenhouse-gas-induced climate change with an optimal fingerprint method. J Clim 9:2281-2306

Hegerl GC, Hasselmann K, Cubasch U, Mitchell JFB, Roeckner E, Voss R, Waszkewitz J (1997) Multi-fingerprint detection and attribution analysis of greenhouse gas, greenhouse gas-plusaerosol and solar forced climate change. Clim Dyn 13:613-634

Hegerl G, Zwiers F (2011) Use of models in detection and attribution of climate change. Wiley Interdisciplinary Reviews-Clim Change, 2:570-591

Hoerling M, Eischeid J, Perlwitz J, Quan X, Zhang T, Pegion P (2012) On the increased frequency of Mediterranean drought. J Clim 25:2146-2161

Hurrell JW (1995) Decadal trends in the North-Atlantic Oscillationregional temperatures and precipitation. Science 269:676-679

Hurrell J, Kushnir Y, Ottersen G, Visbeck M (2003) The North Atlantic oscillation: climatic significance and environmental impact, chapter an overview of the north atlantic oscillation. American Geophysical Union, Washington DC, pp 1-35

Jones PW (1999) First- and second-order conservative remapping schemes for grids in spherical coordinates. Mon Wea Rev 127:2204-2210

Kalnay E et al (1996) The NCEP/NCAR 40-year reanalysis project. Bull Am Meteorol Soc 77:437-471

Lambert FH, Stott PA, Allen MR, Palmer MA (2004) Detection and attribution of changes in 20th century land precipitation. Geophys Res Lett 31:L10203 
Lambert FH, Gillett NP, Stone DA, Huntingford C (2005) Attribution studies of observed land precipitation changes with nine coupled models. Geophys Res Lett 32:L18704

Lionello P, Malanotte-Rizzoli P, Boscolo R, Alpert P, Artale V, Li L, Luterbacher J, May W, Trigo R, Tsimplis M, Ulbrich U, Xoplaki E (2006) The Mediterranean climate: an overview of the main characteristics and issues. In: Lionello P, Malanotte-Rizzoli P, Boscolo R (eds) Mediterranean climate variability. Developments in Earth and Environmental Sciences 4, Elsevier, Amsterdam

Lionello P, Giorgi F (2008) Winter precipitation and cyclones in the Mediterranean region: future climate scenarios in a regional simulation. Adv Geosci 12:153-158

Lucarini V, Russell GL (2002) Comparison of mean climate trends in the Northern Hemisphere between National Centers for Environmental Prediction and two atmosphere-ocean model forced runs. J Geophys Res-Atmos 107:4270

Matti C, Pauling A, Kuettel M, Wanner H (2009) Winter precipitation trends for two selected European regions over the last 500 years and their possible dynamical background. Theor Appl Climatol 95:9-26

Mariotti A and Dell'Aquila A (2011) Decadal climate variability in the Mediterranean region: roles of large-scale forcings and regional processes. Clim Dyn. doi:10.1007/s00382-011-1056-7

Mariotti A (2010) Recent changes in the mediterranean water cycle: a pathway toward long-term regional hydroclimatic change? J Clim 23:1513-1525

Meehl GA et al (2007) The WCRP CMIP3 multi-model dataset-a new era in climate change research. Bull Am Meteorol Soc 88:1383-1394

Min SK, Zhang XB, Zwiers FW, Hegerl GC (2011) Human contribution to more-intense precipitation extremes. Nature 470:376-379

Mitchell TD, Jones PD (2005) An improved method of constructing a database of monthly climate observations and associated highresolution grids. Int J Clim 25:693-712

Osborn TJ (2004) Simulating the winter North Atlantic Oscillation: the roles of internal variability and greenhouse gas forcing. Clim Dyn 22:605-623

Osborn TJ (2006) Recent variations in the winter North Atlantice Oscillation. Weather 61:34-45

Quadrelli R, Pavan V, Molteni F (2001) Wintertime variability of Mediterranean precipitation and its links with large-scale circulation anomalies. Clim Dyn 17:457-466
Raisanen J, Hansson U, Ullerstig A, Doscher R, Graham LP, Jones C, Meier HEM, Samuelsson P, Willen U (2004) European climate in the late twenty-first century: regional simulations with two driving global models and two forcing scenarios. Clim Dyn 22:13-31

Rudolf B, Beck C, Grieser J, Schneider U (2005) Global Precipitation Climatology Centre (GPCC), DWD. Internet publication, pp 1-8

Santer BD et al. (2011) Separating signal and noise in atmospheric temperature changes: the importance of timescale. J Geophys Res-Atmos 116: D22105

Somot S, Sevault F, Deque M, Crepon M (2008) 21st century climate change scenario for the Mediterranean using a coupled atmosphereocean regional climate model. Glob Planet Change 63:12-126

Stephenson DB, Pavan V, Collins M, Junge MM, Quadrelli R (2006) North Atlantic Oscillation response to transient greenhouse gas forcing and the impact on European winter climate: a CMIP2 multi-model assessment. Clim Dyn 27:401-420

Stone DA, Allen MR, Stott PA, Pall P, Min SK, Nozawa T, Yukimoto $S$ (2009) The detection and attribution of human influence on climate. Ann Rev Environ Res 34:1-16

Stott PA, Tett SFB, Jones GS, Allen MR, Mitchell JFB, Jenkins GJ (2000) External control of 20th century temperature by natural and anthropogenic forcings. Science 290:2133-2137

Taylor KE, Stouffer RJ, Meehl GA (2012) An Overview of CMIP5 and the experiment design. Bull Amer Meteor Soc 93. doi: 10.1175/BAMS-D-11-00094.1

Vecchi GA, Clement A, Soden BJ (2008) Pacific signature of global warming: El Ninõ or La Ninã? Eos, Trans Am Geophys Union 89. doi:10.1029/2008EO090002

Willmott CJ et al (1985) Small-scale climate maps: a sensitivity analysis of some common assumptions associated with gridpoint interpolation and contouring. Am Cartogr 1:5-16

Xoplaki E, Luterbacher J, Burkard R, Patrikas I, Maheras P (2000) Connection between the large-scale $500 \mathrm{hPa}$ geopotential height fields and precipitation over Greece during wintertime. Clim Res 14:129-146

Xoplaki E (2002) Climate variability over the Mediterranean. PhD thesis, University of Bern, Switzerland

Xoplaki E, Gonzalez-Rouco JF, Luterbacher J, Wanner H (2004) Wet season Mediterranean precipitation variability: influence of large-scale dynamics and trends. Clim Dyn 23:63-78

Zhang X et al (2007) Detection of human influence on twentiethcentury precipitation trends. Nature 448:461-465. doi: 10.1038/nature06025 